\title{
La contaminación ambiental en los acuíferos de Ecuador.
}

\section{Necesidad de su reversión desde las políticas públicas con enfoque bioético}

\section{The environmental contamination in the water-bearing to Ecuador.}

\section{Need of his reversion from the public policies with bioethics focus}

\author{
*Lucas Guanoquiza Tello ${ }^{1}$, **Alcides Antúnez Sánchez ${ }^{2}$ \\ ${ }^{1}$ Licenciado en Abogacía. Abogado de los Tribunales de Ecuador. Profesor de Derecho en la \\ Universidad Técnica de Cotopaxi; ${ }^{2}$ Licenciado en Derecho. Magister en Asesoría Jurídica. \\ Profesor Auxiliar. Imparte Derecho Ambiental y Mercantil. Facultad de Ciencias \\ Económicas y Sociales. Departamento de Derecho. Universidad de Granma. \\ *lucasguanoquiza@yahoo.es,**aantunez@udg.co.cu, antunez63@nauta.cu
}

Fecha de recepción: 21/02/2018 Fecha de aceptación: 15/06/2019 Publicado: 30/06/2019

\section{Resumen}

El Ecuador es un país rico en recursos hídricos. La interacción del hombre con la biosfera suscita problemas: contaminación del suelo, aire y agua; y cuestiones: hambre y perdidas de flora y fauna. Estas interrogantes pertenecen a la ecología y a la bioética. En América Latina, el reconocimiento del agua como un derecho humano fundamental y como sujeto de derechos dentro del marco de los derechos de la naturaleza en la nación ecuatoriana, constituye un paso indispensable para precautelar la seguridad hídrica en los territorios, que garantice el efectivo goce y ejercicio de los derechos a una vida digna, salud, alimentación, vivienda, cultura, ambiente sano y la permanencia de los ciclos naturales del agua como un bien desde los pueblos originarios. El análisis del agua tiene múltiples análisis en cantidad, calidad y 
distribución de los recursos hídricos, en la interpretación de lo que sucede con el agua en el Ecuador. Uno de los aspectos considerados aún con debilidad es el referido a la calidad, afectada por actividades y procesos contaminantes que plantean una ausencia de políticas y acciones estatales claras y efectivas como un complejo fenómeno social, económico y ambiental, que constituye uno de los más serios obstáculos para el "buen vivir". Necesitado de procesos de formación ambiental desde la bioética.

Palabras clave: Agua, contaminación, derechos, bioética, buen vivir.

\begin{abstract}
Ecuador is a rich country in hydric resources. The man's interaction with the biosphere provokes problems: Contamination of the ground, air and water; And issues: Hunger and losses of flora and wildlife. These questions belong to ecology and to the bioethics. In Latin America, the recognition of the water like a human fundamental right and like subject of rights within the frame of the rights of the nature at the Ecuadorian nation, the hydric certainty at the territories constitutes an indispensable step for pre-preventive, that you guarantee the cash enjoy and exercise of the rights to a worthy life, health, nutrition, house, culture, sound environment and the permanence of the natural cycles of the water like a good from the originating towns. The analysis of water has multiple analyses in bulk, quality and allocation of resources hydric, in the interpretation so that it happens with the water in the Ecuador. One of the aspects considered still with weakness is the referred to quality, affected for activities and contaminating processes that they present an absence of policies and stateowned obvious and effective actions like a complex social, cost-reducing and environmental phenomenon, that it constitutes one of the more serious obstacles for the good living. Needy of processes of environmental formation from the bioethics.
\end{abstract}


Key words: Water, contamination, rights, bioethics, good living.

\section{Introducción}

A nivel global, desde hace varias décadas desde el siglo pasado, se ha evidenciado una profunda crisis de sostenibilidad de los ecosistemas naturales -entre ellos los acuáticos-, surge como resultado de la construcción de sociedades modernas, que sustentan el desarrollo en modelos de industrialización y producción extractivista, lo cual permite percibir al agua dulce como un "recurso inagotable", agravada con los efectos adversos del cambio climático en el siglo XXI (Mejer, 2003).

La Tierra, con sus diversas y abundantes formas de vida, que incluyen a más de 6.000 millones de seres humanos, se enfrenta desde el comienzo del siglo XXI con una grave crisis del agua. El agua, como uno de estos recursos naturales, ha estado siempre vinculada siempre a la supervivencia y desarrollo humano, y por ello es un bien público que goza de especial protección en los ordenamientos jurídicos. Desde el Derecho Internacional, y desde la Declaración Universal de los Derechos Humanos de 1948, se establece que toda persona tiene derecho a un nivel de vida suficiente para asegurar su salud y bienestar, incluido intrínsecamente el derecho humano al agua, por su carácter vital (Asamblea General de Naciones Unidas, 1948; Fernández, 1996; Pisani 1996).

Ello permite reseñar que el agua es un bien indispensable para la vida y por ello tiene un valor intrínseco, apreciable cultural, social y ambientalmente, pues no se considera únicamente como una necesidad humana, sino se configura como un derecho humano. Esto implica descartar la idea de conceptualizar al agua como un "recurso" valorable en dinero y reconocerla como un bien común de uso púbico y por lo tanto está fuera del comercio; pero 
también debe considerarse las varias dimensiones del agua: como un bien social, en tanto es indispensable para la garantía de otros derechos; como un bien ambiental, pues su existencia es vital para mantener el equilibrio de los ecosistemas naturales y; como bien cultural, pues se valora de acuerdo a los usos culturales, asociados con el significado, trascendencia y manejo tradicional del agua por parte de las comunidades, pueblos y nacionalidades.

Es por ello, que reconocer el derecho al agua como un derecho humano fundamental, en un contexto integral y no restrictivo, analizando la totalidad de sus dimensiones que garanticen el ejercicio de otros derechos interdependientes como la salud, la alimentación, el saneamiento, la vida digna, la vivienda, la cultura, un ambiente sano, entre otros. Resolver la crisis del agua es uno de los diversos desafíos con los que la humanidad se enfrenta en este tercer milenio. La crisis del agua debe situarse en una perspectiva más amplia de solución de problemas y resolución de conflictos en materia ambiental que hoy acontecen.

En la región de América Latina, el reconocimiento del agua como un derecho humano fundamental y como sujeto de derechos dentro del marco de los derechos de la naturaleza en la nación ecuatoriana, constituye un paso indispensable para precautelar la seguridad hídrica en los territorios, que garantice el efectivo goce y ejercicio de los derechos a una vida digna, salud, alimentación, vivienda, cultura, ambiente sano y la permanencia de los ciclos naturales del agua como un bien desde los pueblos originarios (Asamblea General de N.U, 2010; Moreno 2000).

El análisis de la temática del agua tiene múltiples entradas, considerar la cantidad, la calidad y la distribución de los recursos hídricos, han sido opciones específicas de interpretación de lo que sucede con el agua en el Ecuador. Sin embargo, uno de los aspectos considerados aún con debilidad es el referido a la calidad, afectada por actividades y procesos contaminantes que plantean una ausencia de políticas y acciones estatales claras y efectivas. 
La contaminación de las aguas es un complejo fenómeno social, económico y ambiental, que constituye uno de los más serios obstáculos para el "buen vivir". Necesitado de procesos de formación ambiental desde la bioética (Elbers, 2013; Gudynas, 2011y Grijalva 2010).

El ensayo está vinculado a los resultados de investigación de la maestría en gestión ambiental, desarrollados entre la Universidad de Cotopaxi y la Universidad de Granma, en la Facultad de Ciencias Agrarias y Técnicas. En el ensayo, se propone como objetivo caracterizar a partir del reconocimiento jurídico en clave constitucional a la protección del recurso agua en Ecuador, los problemas vinculados a la contaminación ambiental en los acuíferos, y la necesidad de su reversión a partir de las políticas públicas desde un enfoque bioético desde la formación ambiental a través del tributo por vertido. Para ello, se han utilizado los métodos de la investigación como el histórico-lógico, el de análisis-síntesis, inducción-deducción, y comparación jurídica.

\section{El Derecho Ambiental ecuatoriano en clave constitucional para la protección del recurso} agua

El Derecho Ambiental, dentro de las ciencias jurídicas, es una de las ramas más dinámicas y de mayor evolución dentro del Derecho Internacional. Las convenciones internacionales se convierten cada vez más, en fuentes importantes de Derecho Ambiental Internacional y de su desarrollo en las legislaciones ambientales nacionales. En la actualidad, cientos de convenciones internacionales han sido expedidas en el campo del Derecho Ambiental. El Programa de las Naciones Unidas para el Medio Ambiente (PNUMA), marcó un hito para estos desarrollos (PNUMA, 2013). 
Por consiguiente, ante la preocupación mundial por la protección ambiental, se aprecia cómo ha alcanzado importancia y magnitud en los últimos años y se ha convertido en temática de interés para la mayoría del empresariado y de los ciudadanos, ante las consecuencias negativas generadas por la contaminación industrial al generar daños ambientales y la observancia inadecuada de proteger a la naturaleza. Esta protección se justiprecia que se exterioriza en tres dimensiones: la económica, la social y la ambiental a partir del desarrollo industrial equilibrado para generar recursos, empleos y promover la educación ambiental como bases del bienestar social y calidad de vida, para lograr el mega principio del desarrollo sostenible del Derecho Ambiental.

Desde la Unión Europa, en este análisis de la problemática de la contaminación ambiental, en la nación de España, Jordano Fraga, desde su postura considera... "el Derecho Ambiental se constituye en un símbolo de preservación y promoción del ambiente y la obligatoriedad de que el hombre implemente y desarrolle un modelo desarrollo sostenible, que permita la coexistencia del hombre-naturaleza”... (Fraga, 2009).

También, Jaquenod de Zogon, expresa su criterio al señalar.

“...el hombre contemporáneo se enfrenta como depredados de la naturaleza, sin tomar conciencia que, en más o menos medida, forma parte de ella, esta acogida por ella, y al desnaturalizarla y alterarla, el mismo se desnaturaliza, altera y traiciona su propia esencia..."(Jaquenod De Zsongon, 1991, 2004, 2005).

Se afirma por esta autora citada que es una combinación de técnicas, reglas e instrumentos jurídicos que se orientan a lograr la protección de todos los elementos que integran el ambiente natural y humano, mediante un conjunto de disposiciones jurídicas que, por su naturaleza interdisciplinar, no admiten regímenes divididos y recíprocamente se condicionan e influyen en el ámbito de todas las ramas jurídicas y científicas existentes. 
Para Martín Mateo, afirma que es un derecho con vocación redistributiva, que iguala desiguales, iguala al afectado, vecino, hombre del pueblo o la comunidad, con los centros de poder político y económico. Caracterizó el derecho ambiental teniendo en cuenta su sustratum ecológico, especialidad singular, énfasis preventivo, componente técnico reglado, vocación redistributiva y primacía de los intereses colectivos (Martín, 1991).

Este autor citado, define al medio ambiente como el conjunto de "aquellos elementos naturales de titularidad común y de características dinámicas en definitiva, el agua y el aire, vehículos básicos de transmisión, soporte y factores esenciales para la existencia del hombre sobre la tierra", donde deben regir los principios de ubicuidad, sostenibilidad, globalidad, subsidiariedad y solidaridad, y se mantengan las propiedades del suelo, el aire y el agua, así como la fauna y la flora y las condiciones ambientales de estas especies, de tal forma que el sistema ecológico se mantenga con sus sistemas subordinados y no sufra alteraciones perjudiciales.

Desde Francia, Prieur, afirma que el Derecho Ambiental no se trata simplemente del conjunto de normas jurídicas que delimitan el medio ambiente, sino que es la expresión de una ética o de una moral del medio ambiente que pretende reducir la contaminación y aumentar la biodiversidad. Por ello, a su criterio el derecho ambiental no constituye solamente un derecho que regula actividades de forma neutra, sino que se trata de un derecho comprometido con la lucha contra la contaminación y la pérdida de biodiversidad. Para este autor francés el derecho ambiental se define, según un criterio finalista, como aquel que, debido a su contenido, contribuye a la salud pública y al mantenimiento de los equilibrios ecológicos, un derecho para el medio ambiente (Prieur, 1991). 
En el Derecho Ambiental en América Latina, la problemática abordada en el cuerpo del ensayo desde Chile, Brañes BALlesteros, define al Derecho Ambiental como aquel conjunto de reglas que se ocupan de la protección jurídica de aquellas condiciones que hacen posible la vida, en todas sus formas. Desde la postura de este autor consultado, la norma jurídica lo ha definido como derecho positivo,

... "es el conjunto de normas jurídicas, que regulan las conductas humanas que pueden influir de manera relevante en los procesos de interacción que tiene lugar entre los sistemas de los organismos vivos (bióticos) y sus sistemas de ambiente (abióticos) mediante la generación de efectos, de los que se esperan una modificación significativa de las condiciones de existencia de dichos organismos"... (Ballesteros, 2003).

En Argentina, Lorenzetti considera desde su posición que el Derecho Ambiental es descodificante (Lorenzetti, 2008). Pigretti, recalca desde sus estudios que el Derecho Ambiental es un derecho tuitivo, protectorio, eticista y solidarista con fuertes componentes de justicia social (Santos, 2016; Caraballo, 2012; Antúnez, 2013). En este mismo sentido, otros estudios realizados en el siglo XXI por Caferrata, Bellorio Clabot, Rinaldi sobre la situación actual del Derecho Ambiental en América Latina, en sus conclusiones coinciden

..."las Constituciones, las Leyes marco o generales, conforman el núcleo duro y estable de la institucionalidad ambiental de los países de la región objeto muestral, para reconocer si estas resultan ser productivas con la aparición de la economía y contabilidad ambiental en pos del desarrollo sustentable vinculadas a la práctica de la auditoría ambiental..."

Luego de valoradas estas ideas, el Derecho Ambiental, se aprecia por los autores del ensayo, como esta rama del derecho nace reconociendo realidades y esgrimiendo reclamos revolucionarios. Se reconoció como un requisito para disfrutar de una vida digna, el derecho a 
un medio de calidad, donde el hombre pueda ejercer sus derechos a la libertad, la igualdad y al disfrute de condiciones de vida adecuadas desde su reconocimiento en el Derecho Ambiental Internacional en 1972.

En consecuencia, en 1987, el Consejo de Administración del PNUMA, adoptó la decisión de presentar ante la Asamblea General el Informe de la Comisión Mundial sobre el Medio Ambiente, bajo el título de "Nuestro Futuro Común" conocido como "Informe Brundtland", y retomó la Carta Mundial el derecho de la diversidad biológica. Con posterioridad, se aprecia como la Cumbre de la Tierra de 1992, generó varios instrumentos jurídicos internacionales como la Declaración de Río sobre Medio Ambiente y Desarrollo, donde se estableció un marco jurídico y un reglamento eficaz, para luego entrar en vigor la Convención sobre la Diversidad Biológica en 1993, y el Convenio de las Naciones Unidas sobre Cambio Climático en 1992, los que han seguido evolucionando con el tiempo hasta la Cumbre del Clima celebrada en París en el 2015, al ser considerado por autores desde sus estudios como Rey Santos, Caraballo Maqueira, Peña Chacón, Antúnez Sánchez (Santos, 2016; Caraballo, 2012y Antúnez, 2013).

Entonces, puede afirmarse que el hecho de que el Derecho Ambiental presenta autonomía científica y didáctica, y una rica normatividad, es la expresión indubitable de su existencia como ciencia y rama jurídica. Se le considera como una nueva rama jurídica que regula la conducta humana estableciendo principios, exigencias, normas y prescripciones jurídicas, otorgando a los sujetos los derechos, las atribuciones, y prohibiciones: es el instrumento, la herramienta legal que regula y autorregula el comportamiento humano ante la conservación de la diversidad biológica, como se señalara en los estudios realizados desde 1998 desde el 
pasado siglo hasta 2016, por Fernández Rubio-Legrá, Rey Santos (Fernandez , 2000 Y SANTOS, 2013).

Al Derecho Ambiental, se le reconoce estar vinculado a ramas y subramas en relación a la contaminación ambiental, como el Derecho Urbanístico en relación a las agua potable y las residuales, el Derecho Minero por su uso en la extracción de minerales, el Derecho Forestal en cuanto al uso del recurso hídrico, el Derecho Agrario relativo al uso del recurso hídrico, el Derecho Tributario en relación al impuesto ambiental, Derecho Penal en relación con la responsabilidad penal, Derecho Administrativo vinculado a los servicios públicos, al dominio público, al Derecho Mercantil por la actividad mercantil con el uso de este recurso, y el Derecho de Aguas, entre otros.

Dentro de los estudios vinculados al Derecho de Aguas, existen varias causas que se han aliado para que se esté disminuyendo el agua en el planeta, entre estas esta la deforestación, lo cual no ayuda a que se produzcan lluvias, otra causa es la contaminación en lagos, ríos y mares; también el uso irracional de los recursos hídricos lo que conlleva a un desperdicio, las bajas eficiencias con que opera la infraestructura, y una equivocada gestión de parte de los organismos encargados de la administración del este recurso; factores que inciden para que exista una inadecuada disponibilidad de este recurso.

Los factores señalados han originado que el agua vaya siendo escasa tanto en calidad y cantidad, situación que se está reflejando en algunas regiones del país en donde la escasez del agua ya es apremiante y esté provocando conflictos y disputas entre usuarios por su aprovechamiento. Así, desde la década de los 90', desde el pasado siglo, varios países de América Latina y, entre ellos Ecuador, donde las organizaciones de la sociedad civil, organizaciones no gubernamentales y movimientos sociales, iniciaron procesos de debate, 
negociación e incidencia para el reconocimiento del agua como un derecho humano fundamental.

El Derecho de Aguas, desde las ciencias jurídicas, ha sido estudiado por Embid Irujo, desde el Derecho Público en España, quien considera que debido a que el agua es un bien de primera necesidad y hasta un derecho humano, prevalece en su gestión un fuerte interés público, lo que justifica la intervención de los poderes públicos para garantizar sus objetivos más elementales, tanto de calidad, como de cantidad o disponibilidad del recurso. De este lado, existe un amplio entramado normativo e institucional que, sobre la base de la planificación hidrológica y el reconocimiento de una sola calificación jurídica, la de bien de dominio público estatal, pretenden garantizar un tratamiento unitario del recurso, cualquiera que sea su origen, superficial o subterráneo. Todo ello, con el fin de regular conforme a este interés general el suministro y precio del agua, la calidad ambiental del bien, su uso y aprovechamiento, la construcción de obras públicas, etc. Siguiendo a este autor consultado, quien refiere que la problemática del agua es un fenómeno general que tiene lugar en muy distintos países con diversos ritmos e intensidades, pero con unas características y dirección que son comunes y advertibles en muy distintas latitudes. En los momentos actuales y dados las certidumbres -y algunas dudas todavía- que presenta el cambio climático y su reflejo sobre los recursos hídricos, es de advertir un incremento en la preocupación por los parámetros de protección y conservación del agua (Embid, 1996, 2006, 2010, 2011).

Aunque este tema del Derecho de Aguas, ha sido abordado por otros autores desde la Unión Europea (Moya, 1951; Palomar, 1986; Retortillo, 1997 y Ortega, 2012) y en la propia nación ecuatoriana (Lloret, 2002; Isch \& Gentes, 2006; Oré, 2009; Paredes, 2011 y Vinueza, 
2011), los que reflejan la necesidad de proteger este recurso por su importancia para la salud humana en pos del desarrollo sostenible, coinciden en la región de América Latina, el reconocimiento del agua es un derecho humano fundamental y como sujeto de derechos dentro del marco de los derechos de la naturaleza en la nación ecuatoriana, constituye un paso indispensable para precautelar la seguridad hídrica en los territorios, que garantice el efectivo goce y ejercicio de los derechos a una vida digna, salud, alimentación, vivienda, cultura, ambiente sano y la permanencia de los ciclos naturales del agua como un bien desde los pueblos originarios.

Para ello, se valora dentro del cuerpo del ensayo como en la Constitución Ecuatoriana del 2008, se garantiza a la población el acceso seguro y permanente al agua, vivir en un medio ambiental sano y ecológicamente equilibrado, resumido como "buen vivir" o "sumak kausay". Con el neoconstitucionalismo ecuatoriano, se aprecia como en este proceso se han incorporado en las constituciones reivindicaciones ancestrales de los pueblos originarios y se han creado nuevos derechos hasta ahora desconocidos en el constitucionalismo tradicional. Es concebido como una recomposición de fuerzas del pasado, antes antagónicas o enemigas, y que hoy recurren a los principios constitucionales para superar sus diferencias y fracturas (Zabala, 2010; Melo, 2009; Prieto, 2012 y Bhrunis, 2010).

A partir de la Constitución de 2008, el Estado ecuatoriano reconoce a la población el derecho humano al agua, esta disposición regulada en el artículo 12, dispone "El derecho humano al agua es fundamental e irrenunciable. El agua constituye patrimonio nacional estratégico de uso público, inalienable, imprescriptible, inembargable y esencial para la vida". Crespo Plaza desde su postura como constitucionalista, expone que las reformas de 1983, introdujeron en la Constitución de 1978, el derecho a vivir en un ambiente sano. Más tarde y luego de la influencia marcada por la Cumbre de Río de 1992, aparecen normas ambientales 
más amplias en la Constitución de 1998. A criterio de este autor referenciado, en la Constitución del 2008, se ensancha la normativa ambiental bajo el enfoque de un paradigma biocéntrico al reconocer derechos a la naturaleza, no sólo impulsado por el derecho internacional y el derecho ambiental comparado sino por una reafirmación de la cosmovisión de las culturas indígenas autóctonas que reconocen el derecho al buen vivir o sumak kawsay y consideran que el ser humano es parte de un sistema natural integral y circular denominado Pacha Mama (Crespo, 1995; 2008 y 2015).

También, ACOSTA refiere desde sus estudios desde la economía, que Ecuador al ser un país privilegiado en cuanto a la disponibilidad del agua, si se comparase con otras regiones en el mundo. Lamentablemente y sobre todo en los últimos años, se ha registrado un permanente deterioro de la calidad e incluso de la cantidad del agua. La pérdida de los páramos y la deforestación creciente explican esta compleja realidad. Igualmente, no se han resuelto los graves problemas derivados del manejo contaminante del agua provocados por la actividad de extracción de crudo y manejo de residuos en la región amazónica. La contaminación ha llegado al extremo de afectar a las 72 cuencas hidrográficas del país. Aunque uno de los puntos en que más se avanzó en la Asamblea Constituyente de Montecristi fue aquél relativo al tratamiento del agua y los recursos hídricos (Acosta, 2010).

La mirada de Martínez Moscoso, desde el Derecho Público ecuatoriano, considera desde su postura que es necesario generar una política que aplique tarifas que permitan alcanzar una eficiencia en el uso de un recurso tan escaso, y que elimine el despilfarro a través de la imposición de un pliego tarifario que castigue el consumo excesivo y que de alguna forma 
premie o beneficie al usuario que menos utiliza el recurso. En el siglo XXI es necesario un uso racional del agua (Moscoso, 2017).

Otro repaso, desde el Derecho Ambiental, realizada por autores ecuatorianos significan los diversos problemas ambientales que inciden en la calidad no adecuada del agua, como una de las facetas más preocupantes del deterioro ambiental en la crisis del agua, que deja ver sus efectos de manera compleja en distintos ámbitos de la realidad ecosistémica y de la actividad humana. Estos se reflejan en la contaminación ambiental por la extracción de hidrocarburos, por la actividad extrativista vinculada a la minería, por la deforestación, por el uso de plaguicidas en los procesos agrícolas, entre otros (Larrea, 2008; Poles, 2010; Vinueza, 2011 y Morales, 2013).

Demuestran que, como hecho histórico-jurídico, la constitución político jurídica de 2008, es cierto que sintetiza un momento histórico, y que en ella se cristalizan diversos procesos sociales acumulados, y se plasma una determinada forma de entender la vida desde la bioética. De hecho, una Constitución no puede ser simplemente el resultado de un ejercicio de jurisprudencia avanzada; a partir de los criterios analizados de los constitucionalistas ecuatorianos en los cambios realizados, como lo sistematizan Borja y Borja, Verdesoto Salgado, Larrea Horguín, Salgado Pesantes, Bhrunis Lemarie, Grijalva Jiménez, postura a la que nos incorporamos (Borja y Borja, 1979; Verdesoto, 1988; Larrea, 1999; Pesantes, 2003; Bhrunis, 2010 y Jiménez, 2012).

Zaffaroni, reseña que en la Constitución del Ecuador:

... "la Tierra asume la condición de sujeto de derechos, en forma expresa", añadiendo que "de este modo el constitucionalismo andino dio el gran salto del ambientalismo a la ecología profunda, es decir, a un verdadero ecologismo constitucional. La invocación de la Pachamama va acompañada de la exigencia de su respecto, que se traduce en la regla 
básica ética del sumak kawsay, que es una expresión quechua que significa buen vivir o pleno vivir y cuyo contenido no es otra cosa que la ética-no la moral individual- que debe regir la acción del estado y conforme a la que también deben relacionarse las personas entre sí y en especial con la naturaleza (...) No se trata del tradicional bien común reducido o limitado a los humanos, sino del bien de todo lo viviente, incluyendo por supuesto a los humanos, entre los que exige complementariedad y equilibrio, no siendo alcanzable individualmente"...(Zaffaroni, 2011).

En esta misma línea e ideas, la protección a los recursos hídricos en Ecuador, se aprecia cómo se reconoció al agua como patrimonio nacional estratégico de uso público, inalienable, imprescriptible, inembargable y esencial para la vida desde la técnica constitucionalista. Ligando íntimamente, su ejercicio al ejercicio de otros derechos humanos como la soberanía alimentaria que garantiza el derecho de la alimentación, la salud, la cultura; el derecho a un ambiente sano; a construir y mantener la identidad cultural; a un hábitat seguro y saludable; y a una vida digna dentro de la Pacha mama.

El agua por ser un recurso natural limitado y un bien público fundamental para la vida y la salud. El derecho humano al agua es indispensable para vivir dignamente y es condición previa para la realización de otros derechos humanos. El derecho humano al agua es el derecho de todos a disponer de agua suficiente, salubre, aceptable, accesible, para el uso personal y doméstico. Una dotación apropiada de agua sana es indispensable para disminuir muertes por causas de deshidratación, enfermedades que se las pueden prevenir con un poco de agua diaria, cuidados de aseo, etc. Y que, como derecho humano, durante milenios, la humanidad ha considerado el agua como un elemento no modificable del globo terráqueo, 
como el aire. En un mundo esencialmente rural, el agua estaba enormemente desconectada de los circuitos económicos ya que la fuente, el río, el brazo de río, el pozo y la cisterna alimentaban a las poblaciones sin ningún costo o muy bajo, dependiendo de la condición servil o no de la mano de obra.

No hay dudas que, la Constitución ecuatoriana de 2008, constituye un marco favorable en materia de derechos y garantías constitucionales, pues define al agua como un derecho humano con carácter fundamental e irrenunciable, y para hacerlo efectivo reconoce que es necesario el acceso al agua en calidad y cantidad suficientes. El texto constitucional, reconoce al agua como patrimonio nacional estratégico de uso público, inalienable imprescriptible, inembargable y esencial para la vida, lo cual implica que el Estado debe asumir el control y decisión del destino de los bienes hídricos, pensando en las necesidades de las generaciones actuales y futuras, de acuerdo a principios constitucionales de sostenibilidad ambiental, precaución, prevención y eficiencia. Tal y como lo pondera el Derecho Ambiental, y autores de esta temática como Caferrata, Brañes Ballesteros, Lorenzetti, Bellorio Clabot, De Besa Antunes, Peña Chacón (Aguirre, 2012).

Para garantizar el ejercicio de este derecho como bien público por los ciudadanos ecuatorianos, el Estado tiene la obligación de adoptar políticas públicas y normas dirigidas a la conservación, recuperación y manejo integral del agua, que incluyen adopción de medidas de precaución y restricción de las actividades que puedan destruir o alterar el equilibrio de los ecosistemas y afectar la calidad y cantidad de agua. Donde a consideración de los autores del ensayo esta la problemática que ocurre con los recursos hídricos en la nación de Ecuador, como es el impuesto por vertido y la fórmula estimulación/recompensa a los sujetos de gestión económica. 
Para ello, se pondera que el derecho humano al agua está íntimamente ligado al cumplimiento de otros derechos humanos, pero también está interrelacionado con el cumplimiento de los derechos de la naturaleza, sobre la base de principios como el respeto a la Pacha Mama y el buen vivir en el contexto político ecuatoriano. Así, el agua, entendida como un bien natural, social y cultural, debe ser analizada desde dos perspectivas: como derecho humano y como sujeto de derechos. Para garantizar la existencia integral del agua, es imprescindible entonces prohibir la contaminación del agua por medio de descargas de vertidos líquidos o sólidos y fijar mecanismos de protección inmediatos.

El derecho al agua no se refiere solo al acceso a la misma, sino que incluye la garantía de calidad del líquido vital. Actuar para prevenir, reducir, controlar, remediar la contaminación, así como brindar reparación adecuada a las poblaciones afectadas, es una responsabilidad de cumplimiento inmediato por parte de las autoridades y la ciudadanía. Esta problemática, consideran los autores que aún no tiene una solución adecuada en el ordenamiento jurídico ecuatoriano, aunque hay múltiples disposiciones jurídicas que protegen al medio ambiente (Crespo, 1995; Pérez y Montalvo, 1999; Poles, 2010; Romero, 2012; Angulo 2013 y Crespo, 2015).

Por consiguiente, se justiprecia que la importancia que tiene hoy la naturaleza y específicamente el recurso agua, radica en que ha dejado de ser un objeto para convertirse en un sujeto de derechos, y esto nos exige a los seres humanos el garantizar su cuidado y conservación, que permita alcanzar el desarrollo sostenible desde la bioética. Es necesario que el agua, como elemento vital que conforma el desarrollo sustentable del planeta, ya que su escasez o abundancia extrema, ocasiona desequilibrios en los hábitats naturales, altera las 
condiciones hidroclimatológicas, modifica las condiciones para el aprovechamiento de los recursos naturales y el bienestar de la población.

Por ello, los autores del ensayo ponderan que es necesario revertir esta situación desde acciones formativas, que se inicien desde la educación ambiental a los servidores públicos y a la ciudadanía, y que estas desde sus contenidos formativos tengan un referente bioético, de esta manera se cumpliría el principio deber-derecho para con la Pacha mama, para preservar los recursos acuíferos y mitigar la contaminación ambiental que hoy pervive en la nación ecuatoriana en pos del desarrollo sostenible.

Particularmente, necesitará de la transversalidad de las políticas públicas para el desarrollo sustentable, ello debe ser una prioridad del sector ambiental, derivada del apoyo y coordinación tanto inter como intragubernamental, sigue siendo un paradigma alcanzarlo dentro de las políticas públicas en materia de proteger al medio ambiente con la aplicación del impuesto por vertido y contravenciones administrativas. Ello tiene la pertinencia de obligar a compartir información y experiencias, habilidades técnicas del personal, y sobre todo voluntades políticas de sus directivos, convirtiéndose en el principal instrumento de trabajo de planeación, consulta pública, atención social, y particularmente de presupuestos, a través de contenidos digitales, de consulta popular en la red de redes. Hay que significar que uno de los pilares de las políticas públicas nacionales, y en cada ámbito de competencia la variable ambiental debe incluirse en la toma de decisiones con un enfoque bioético.

\section{La contaminación ambiental del recurso agua. Su dimensión económica, ecológica,}

\section{social, cultural y turística en la nación ecuatoriana}

Ecuador, con sus 40 áreas naturales protegidas, lo convierten en el primer país mega diverso del planeta, está sujeto a ciertas limitaciones de explotar recursos en las áreas de conservación tanto por mandato constitucional como por los compromisos que ha asumido a 
nivel internacional para la conservación de determinadas áreas, por haber ratificado convenios como el Convenio sobre Patrimonio Natural, el Convenio sobre Diversidad Biológica, la Convención en contra del Tráfico Ilegal de especies de Flora y Fauna Silvestre (CITES), etc.; además algunas de estas áreas protegidas están ubicadas en los lugares estratégicos donde existen yacimientos de petróleo y minería.

La contaminación, es definida en la literatura científica como la presencia o incorporación al ambiente de sustancias o elementos tóxicos que son perjudiciales para el hombre o los ecosistemas (seres vivos), al existir diferentes tipos de contaminación. Hoy la contaminación, sigue siendo un tema preocupante en el mundo entero porque vivimos colapsado de ciertas enfermedades a causa del agua que tomamos a diario, y también por respirar aire contaminado. Por consiguiente, la contaminación ambiental, es concebida como la que produce alteraciones al medio ambiente dañándolo de manera leve o grave, o destruyéndolo por completo. También debemos tener en cuenta el factor tiempo, ya que el daño puede ser temporal o continuo.

Entre una de las causas de esta contaminación ambiental, se aprecia con el rápido crecimiento urbano e industrial ocasiona enormes desechos residuales potencialmente nocivos que han sido vertidos y diluidos en la atmósfera, en el agua o en los suelos, esperando que se biodegradasen naturalmente. Como el carácter depurador del medio natural es limitado, el resultado ha sido que la contaminación ha afectado a la salud de muchas personas, ha producido daños generalizados en la vegetación, en la fauna o en el medio ambiente al no usar tecnologías limpias. 
Ecuador, al ingresar a la llamada Revolución Verde a mediados del siglo pasado, y ser uno de los países con mayores reservas de agua en América del Sur; las aguas ocupan una elevada porción en relación con las tierras en la superficie, presentándose en forma de océanos y mares, hielos polares y glaciares, aguas subterráneas y las aguas terrestres que comprenden ríos, lagunas y lagos. El líquido más abundante del planeta lo constituye el agua, representando el recurso natural de mayor importancia y la base de toda forma de vida. Tiene como característica su ubicuidad, estando presente en cualquier rincón del mundo, incluso integrada en todos los seres vivos, es la única materia que puede estar en un mismo lugar en estado líquido, sólido y gaseoso.

El agua, concebida como el fundamento de la vida y es un factor decisivo en la distribución y movilidad de las especies y entre ellas, la especie humana que tiene inteligencia y en consecuencia la capacidad y responsabilidad de gestionar el medio natural con criterios de sostenibilidad. El agua, es el bien más preciado que existe, por lo que los gobiernos deben usar todos los medios para conservar su pureza y evitar que la contaminación se apodere de este elemento hídrico, sin el cual, la vida no tardaría en desaparecer. Sin embargo, existen problemas con el manejo de este elemento, al no existir un adecuado control público por parte de las autoridades ambientales y no tener una adecuada cultura ambiental que incida en su protección sigue siendo desfavorable.

Vinculada en contexto al desarrollo sostenible, término que aparece a finales del siglo XX, y que, como paradigma del Derecho Ambiental del siglo XXI, junto con las primeras preocupaciones sobre el ambiente y desarrollo, según la primera estrategia mundial de la conservación en 1981, se establece que "para que el desarrollo sea sostenible, debía considerar los factores económicos y sociales, junto a la base de recursos vivos e inanimados ofrecidos por los ecosistemas desde la perspectiva de la bioética". 
Esto dice que el proceso que está siguiéndose en Ecuador es el incremento de la ganancia del capital a costa de un deterioro creciente de los recursos naturales está ocasionando daños al medio ambiente. Ello incide que en Ecuador el $85 \%$ del agua utilizada se destina al riego en los procesos agrícolas. Otro ejemplo de lo referido, es que las empresas transnacionales que producen productos destinados a la exportación reciben la mayoría de esta agua. El país es uno de los principales exportadores de flores del mundo junto a Holanda y Colombia. Las flores de exportación que produce cuentan con un riego que cubre el 100\% de la superficie de los cultivos.

También, otra fuente de la contaminación, es por el agua superficial, proveniente de fuentes domésticas ocurre alrededor de todo el país, especialmente cerca de las áreas altamente pobladas. Casi todos los ríos del país cercanos a las áreas urbanas tienen altos niveles de DBO (demanda bioquímica de oxígeno), nitrógeno y fósforo. La mayoría de la contaminación proviene de desperdicios domésticos, químicos y agrícolas. La presencia de tantos residuos domésticos, fertilizantes, pesticidas y desechos industriales altera la flora y fauna acuáticas.

La contaminación del río, además de ser un problema ambiental, es también una problemática social ya que involucra directa e indirectamente a los seres humanos, quienes al mismo tiempo de ser los causantes del daño ambiental también tienen la enorme responsabilidad de convertirse en los gestores en la búsqueda de estrategias de solución para propiciar el rescate y conservación de este importante recurso natural.

Empero, a pesar del gran valor cultural que encierra este hecho, no se puede negar los problemas ambientales que afectan a este recurso natural, lo que a su vez trae consigo la 
pérdida de manifestaciones culturales de grupos étnicos que ven en este afluente parte de su cosmovisión andina y quienes se han visto afectados al volverse cada día más crítica la contaminación lo cual podría traer como consecuencia la desaparición de sus manifestaciones. Tiene también un gran potencial turístico el agua; sin embargo, el valor paisajístico de este recurso se ve afectado por la contaminación ambiental y esto a su vez impide el considerarlo como un lugar para la atracción turística.

\section{La contaminación ambiental en las cuencas acuíferas del Ecuador}

El derecho al agua, aunque no se encuentre reconocido dentro de los derechos humanos como una norma expresa o derecho fundamental, es un derecho innato al ser humano, debido a que sin agua no existiría vida en nuestro planeta. De allí su importancia, que en la actualidad se encuentra enmarcado en tratados e instrumentos jurídicos internacionales. El agua es esencial para la vida. La cantidad de agua dulce existente en la tierra es limitada, y su calidad está sometida a una presión constante. La conservación de la calidad del agua dulce es importante para el suministro de agua de bebida, la producción de alimentos y el uso recreativo. La calidad del agua puede verse comprometida por la presencia de agentes infecciosos, productos químicos tóxicos o radiaciones. (Organización Mundial de la Salud, OMS).

Para la OMS el agua está contaminada cuando su composición se haya alterado de modo que no reúna las condiciones necesarias para ser utilizada beneficiosamente en el consumo del órgano y de los animales. Se afirma desde la literatura científica que, los ríos, cuencas y ecosistemas acuáticos son el motor biológico del planeta. El agua es la fuente de vida de todo ser vivo del planeta, constituye un elemento vital para la naturaleza y para la existencia de los seres humanos, hasta el momento no hay estudios que demuestren que existan seres que no 
necesiten de este elemento natural para vivir, de allí la importancia que tiene el garantizar que el agua que consumen los seres vivos en general sea adecuada y no comprometa su existencia. Además, el agua es un elemento que tiene múltiples usos desde fuente para la producción agrícola, hasta materia prima en la producción de energía hidráulica, por lo tanto, es indispensable que se establezcan regulaciones sobre su uso y aprovechamiento.

Es importante recordar que el agua tiene una relevancia de alto rango para los Estados, debido a que su disponibilidad define las líneas de pobreza o desarrollo, de modo que una gestión acertada de su recurso garantizaría el mejoramiento de la calidad de vida de sus habitantes. En contraposición, la destrucción de bosques y humedales, la contaminación de esteros y ríos devenido por la explotación de recursos, en especial de actividades de gran impacto como la actividad petrolera o minera que en su desarrollo requiere el consumo de grandes cantidades de agua, significan impactos sobre cuerpos de agua, sean estas lagunas, riachuelos, ríos o mares que se ven impactados tanto en las fases de descargas naturales y/o por efectos de derrames "accidentales" o provocados.

Por ello, se concibe que la contaminación hídrica es la presencia en el agua de contaminantes en cantidad y tiempo suficiente para provocar efectos adversos a la salud y al medio ambiente, (materia orgánica, nutrientes, sólidos suspendidos, metales pesados, hidrocarburos, sales, organismos patógenos, calor). Además de ser una sustancia imprescindible para la vida por sus múltiples propiedades es ampliamente utilizada en las actividades diarias como: la agricultura (70\% al $80 \%)$, la industria (20\%), el uso doméstico (6\%), entre otras, convirtiéndose en unos de los recursos más apreciados en planeta. La importancia de conservar y mantener la calidad de las fuentes naturales, de manera que se 
garantice su sostenibilidad y el aprovechamiento de las futuras generaciones. (Organización de las Naciones Unidas, ONU).

Ente las causales de contaminación ambiental en la nación ecuatoriana son:

La contaminación del agua causada por la inadecuada disposición y eliminación de residuos, constituye uno de los principales problemas que afecta a la calidad del agua en el Ecuador. Se estima que, por debajo de los 2000 metros de altitud, los cauces de agua en el Ecuador están contaminados especialmente por desechos de las actividades industriales y falta de sistemas de remediación de aguas servidas, IsCH (ISCH \& GENTES, 2006).

Las provocadas especialmente por aguas residuales de procesos industriales y/o manufactureros de transformación o explotación (minería, hidrocarburos, metalúrgicos, textiles) y generación de energía.

Las actividades industriales que causan daño en los ecosistemas naturales son la extracción de madera con fines comerciales, la agroindustria, la extracción de petróleo y minerales y la construcción de proyectos hidroeléctricos y los denominados proyectos multipropósito.

La agricultura, es otra de las fuentes de contaminación, al usar en la misma fertilizantes, plaguicidas y herbicidas que utilizan los agricultores para la fertibilidad de la tierra y para proteger los cultivos, de buenas cosechas y de las plagas, estos productos a través de las lluvias y de los riegos arrastran a los ríos y vertientes y por ende contaminan el agua. Producida por la utilización de fertilizantes, pesticidas, nutrientes; además desechos de actividades agroindustriales. El uso de pesticidas en la producción agrícola tiene impactos nocivos en la salud humana y en el ambiente, especialmente en el agua y la tierra.

La contaminación del agua por extracción de petróleo puede darse por varias actividades durante el proceso: contaminación por desechos sólidos y químicos, por lodos de perforación, por accidentes y derrames, por operación de los pozos, alteración de los cursos de agua, entre 
otros. Las fases de explotación petrolera utilizan grandes cantidades de agua en los procesos, por lo que es indispensable que exista un control adecuado del caudal y tipo de concesiones de agua.

Los impactos de la explotación minera de mediana y gran escala en el agua, afectan tanto la disponibilidad -presente y futura- del agua, así como su calidad, pues por lo general las zonas donde existen reservas de minerales generalmente están ubicadas en centros poblados y cerca de cursos de agua usados por la población.

Otra forma de contaminación son las descargas de desechos provenientes de la crianza de animales que son vertidos en los ríos y en algunos casos cerca de los centros poblados, lo cual general graves problemas de salud y contaminación al ambiente.

Estos elementos, valoran los autores del ensayo, son necesarios revertirlos con una actitud proambiental, que parta de las políticas públicas del Estado a cumplirse por los servidores públicos desde la bioética, claro que tiene una incidencia en especial a los ciudadanos, en especial a los pueblos originarios, si se tiene en cuenta que la nación ecuatoriana es uno de los países con mayores reservas acuíferas; para ello es necesario procesos de formación ambiental y modificar las políticas públicas en relación a la política impositiva que incluya la contaminación por vertido y la exigencia de la responsabilidad administrativa a las empresas pública y la privada.

\section{Las políticas públicas ambientales desde la perspectiva bioética para revertir la contaminación ambiental}

Las políticas públicas ambientales son concebidas como el conjunto de esfuerzos políticos para conservar las bases naturales de la vida humana y conseguir un desarrollo sostenible. Son 
el conjunto de objetivos, principios, criterios y orientaciones generales para la protección del medio ambiente de una sociedad particular. Entonces, puede afirmarse que la política ambiental está estrechamente interrelacionada con otros sectores políticos, cuyas decisiones y programas influyen directamente en sus resultados y requiere un alto nivel de coordinación. Bajo estas premisas, todo el ámbito del marco Institucional debe estar construido por ciertas condiciones que son necesarias para la aplicación y práctica efectiva de las políticas ambientales.

Es decir que tienen que solucionar sus problemas tecnológicos (como enfrentar desde la ciencia y la técnica, los problemas de contaminación o prevención), problemas sociales (como incluir a la ciudadanía en la gestión ambiental y lograr el consenso, frente a los posibles conflictos que se presentaren), problemas legales (de qué manera se puede sancionar, administrar o hacer cumplir las políticas de gestión ambiental, tiene que ver con la existencia de ordenanzas al respecto), problemas políticos (como la inestabilidad política o la incertidumbre, genera posibilidades de gestión eficientes y con seguimiento efectivo, para el logro de los objetivos); y, los problemas económicos (el nivel de financiamiento necesaria para ejecutar la política de gestión o su falta de recursos impide su aplicación o evaluación)

En todo este contexto, la bioética, en relación con el medio ambiente, se inscribe con una aspiración en concreto: establecer la eticidad de las relaciones del hombre con la naturaleza, es decir, de terminar no que la preservación del ambiente sea un deber y una necesidad -lo cual ya ha sido formulado y suficientemente reiterado por otras disciplinas-, sino establecer un campo de reflexión sobre las relaciones del hombre, como especie y como grupo, en relación con la biosfera, de modo que se investiguen no solo los mecanismos de preservación del ambiente, sino también la legitimidad ética de los mismos, dentro de una filosofía de la 
naturaleza que justifique el lugar del hombre y el sentido de su acción sobre sí mismo y el ecosistema (Sarmiento, 2001; Barragan \& Serna, 2006 y Cuenca, 2006).

La Ley de Gestión Ambiental, señala que la Autoridad Ambiental Nacional será ejercida por el Ministerio del ramo, que actuará como instancia rectora, coordinadora y reguladora del sistema nacional descentralizado de gestión ambiental, desde donde se dictan normas de manejo ambiental y evaluación de impactos ambientales, y definir sistemas de control y seguimiento de las normas y parámetros y régimen de permisos y licencias sobre actividades potencialmente contaminantes, a partir de la función inspectiva (Antúnez, 2016).

El Ministerio de Ambiente -Autoridad Ambiental Nacional- tiene como objetivo institucional prevenir la contaminación, mantener y recuperar la calidad ambiental; así como mantener, regular y mejorar la cantidad y calidad del agua, manejando sustentablemente las cuencas hidrográficas. La Contraloría General del Estado es la entidad encargada de auditar los procedimientos de realización y aprobación de los estudios y evaluaciones de impacto ambiental, determinando la validez y eficacia de los mismos; así como puede evaluar la eficiencia, efectividad y economía de los planes de prevención, control y mitigación de impactos negativos de los proyectos, obras o actividades, a partir de la ejecución de la auditoría ambiental (Antúnez, 2016).

Entre otras leyes de carácter ambiental que actualmente existen en el Ecuador podemos mencionar la Ley Forestal y de conservación de áreas naturales y vida silvestre, la Ley de aguas, la Ley de desarrollo agrario, etc. Pero sin duda las leyes más polémicas y de mayor preocupación para la sociedad ecuatoriana, son aquellas que tienen relación a las actividades 
extractivas. Al respecto, debemos mencionar que estas actividades en el ámbito ambiental, están reguladas bajo reglamentos.

En efecto, dentro de las actividades hidrocarburíferas las disposiciones que establecen la forma como deben comportarse dichas actividades con el ambiente, están sujetas a lo establecido en el Reglamento Ambiental para Operaciones Hidrocarburíferas, a pesar de que existe una Ley de Hidrocarburos, esta no contiene disposiciones respecto a otras variables de gran importancia, como los mecanismos de participación para estas actividades, la intervención petrolera en zonas protegidas, la intervención en comunidades indígenas, la relación de la actividad petrolera respecto al derecho al agua, al uso del suelo, como se desarrolla la fase de exploración, el comportamiento de las instituciones en las actividades de explotación, etc.

En la parte penal, el Código Penal ecuatoriano tiene un capitulo especifico en donde se establecen los delitos ambientales con sus respectivas penas, que hacen referencia a la figura jurídica de “delito ecológico". En el año 2000, en Ecuador, se incorporó al Código Penal los delitos contra el medio ambiente y las contravenciones ambientales. Catorce años después de este hecho jurídico, el Código Orgánico Integral Penal definió las normas para sancionar a los distintos tipos de delitos: contra el ambiente y la naturaleza o Pacha Mama, contra la biodiversidad, contra los recursos naturales, contra la gestión ambiental y contra los recursos naturales no renovables. A partir de aquí, se han registrado derrames petroleros en el mar y en los ríos, el comercio de especies en peligro de extinción, entre otros delitos como la caza furtiva por nacionales y foráneos de especies marítimas en peligro de extinción (Albán, 2007; Guanoquiza, 2017 y Albán, 2016).

\subsection{La formación jurídica ambiental desde un enfoque bioético para alcanzar la cultura} ambiental en la nación ecuatoriana 
La educación está inmersa en una profunda revolución, condicionada por las exigencias que a ella le plantea la sociedad actual, se aboga por un profesional competente cuyos modos de actuación estén en correspondencia con el desarrollo de la educación científica del siglo XXI. La educación tiene la misión de permitir a todos sin excepción hacer fructificar todos sus talentos y todas sus capacidades de creación, lo que implica que cada uno pueda responsabilizarse de sí mismo y realizar su proyecto personal.

Lleva a reflexionar a los ensayistas sobre la situación a la que se enfrenta la población mundial, la que se traduce en un desafío para los educadores del mundo, como los encargados de formar a las nuevas generaciones para cumplir su encargo social en este siglo XXI. Los impulsos producidos por la Conferencia sobre "Medio Ambiente y Desarrollo" de Río de Janeiro en 1992, fueron recibidos por la mayoría de los estados de la Tierra. Estos fueron puestos sobre el banco de pruebas en el 2002, en la Conferencia de Johannesburgo. Con la firma de la Agenda 21, se han puesto de acuerdo, alrededor de 180 Estados, en el modelo de la sustentabilidad, para la conformación de toda su política. En la Agenda 21, es asignado un importante rol a las universidades, para responder en su función de intermediarias del saber, y por otro lado en su función de investigación y producción de conocimientos.

GoNZÁLEZ Novo, señala que la formación ambiental, ha sido concebida desde la Conferencia de Tbilisi como el proceso de construcción de un saber interdisciplinario y de nuevos métodos holísticos para analizar los complejos procesos socios ambientales que emergen del cambio global. Toda vez que, en el ámbito del Programa de Naciones Unidas para el Medio Ambiente "la formación ambiental es comprendida, como una educación 
ambiental especializada, en cuanto que se dirige a un grupo restringido de profesionales" (Gonzáles, 1998 y Novo, 2000).

Leff Zimerman, considera desde sus estudios

..."la necesidad de internalizar un saber ambiental emergente en todo un conjunto de disciplinas, tanto de las ciencias naturales como sociales, para construir un conocimiento capaz de captar la multicausalidad y las relaciones de interdependencia de los procesos de orden natural y social que determinan los cambios socioambientales, así como para construir un saber y unaracionalidad social orientada hacia los objetivos de un desarrollo sustentable, equitativo y duradero"... (Leff, 2000).

Los nuevos retos plantean la redimensión de la educación ambiental como proceso ante la pobreza, las modalidades de consumo, los problemas de población, salud, economía, desarrollo social y humano, paz y seguridad, así como a la democracia y los derechos humanos como premisas fundamentales en el proceso de gestión educativa ambiental. Ello implica crear y diseñar espacios educativos, sociales, culturales y ambientales que permitan el intercambio y la pluralidad de saberes en el camino sugerente de vislumbrar un ser humano que comprenda e integre la complejidad del mundo, donde se necesita conocerlos saberes en materia ambiental con un enfoque bioético.

Los autores del ensayo consideran que la educación jurídica ambiental busca la formación de una cultura jurídica ambiental, sin embargo, las ciencias de la educación no se han ocupado de este aspecto en profundidad de manera adecuada; no obstante, sobre cultura jurídica o cultura de la legalidad se ha particularizado el conocimiento de los derechos y de las obligaciones, de las prácticas y costumbres a las que se les atribuyen en algunos sistemas de derecho una función razonable y relevante en la vida colectiva, que permita dar cumplimiento 
al principio de legalidad, el que desde el Derecho Público se pondera con un enfoque desde la bioética.

Como hecho social, hay que significar que la educación jurídica ambiental salió de las Escuelas de Derecho y comenzó a penetrar el campo profesional por la acción de la ciencia y la tecnología sobre el medio ambiente, pero el enfoque interdisciplinario sigue siendo un objetivo por alcanzarse de manera adecuada en el sistema educacional y no verlo de manera fragmentada, en pos del desarrollo sostenible como política pública. Contextualizado en la aplicación del control público ambiental, ya sea a través de la función inspectiva o la auditora (Antúnez, 2016, 2015).

\section{Asidero jurídico de la protección al bien público agua en el ordenamiento jurídico ecuatoriano con un enfoque bioético}

El asidero jurídico de la protección al bien público agua dentro del ordenamiento jurídico ecuatoriano con enfoque bioético, se justiprecia que parte del derecho a vivir en un medio ambiente libre de contaminación, fue reconocido mediante reforma constitucional en el año de 1983. Desde entonces, se aprecia que las reformas y codificaciones constitucionales han estructurado un marco normativo orientado a la tutela del ambiente. En 1996, desde el pasado siglo, entró en vigencia una codificación de la Constitución Política, que también incluyó importantes aspectos ambientales en estos términos.

En esta misma cuerda, la Constitución Política de la República del Ecuador de 1998, como continuidad, sistematizó las reformas de 1983 y 1996, en función de los principios contenidos en la Declaración de Río de Janeiro sobre el Medio Ambiente y el Desarrollo de 1992, desde el siglo XX. Este proceso, que se denomina constitucionalismo ambiental ecuatoriano, se 
caracteriza por el reconocimiento de derechos y deberes ambientales en la Constitución de 2008, donde se mantiene el esquema de derechos, deberes y garantías ambientales, al que suma una sistematización de las reglas ambientales aplicables a la conservación de la biodiversidad y la gestión ambiental.

Demuestra que, el objeto de los derechos ambientales está enmarcado por la calidad ambiental y el equilibrio ecológico, lo cual es coherente con la aproximación doctrinaria del Derecho Ambiental, en tanto disciplina jurídica, dentro de la cual se examinan aspectos relativos a la gestión ambiental y la conservación de la diversidad biológica incluyendo, por ejemplo, la prevención y el control de la contaminación ambiental, la gestión de los ecosistemas protegidos o la protección de la vida silvestre desde la bioética.

GRIJALVA JiMÉNEZ, desde sus estudios sobre el Derecho Ambiental ecuatoriano, sostiene que, los derechos de la naturaleza "tienen necesariamente el efecto de elevar los estándares de protección ambiental" (Grijalva, 2010). Luego es desarrollado en cuerpos jurídicos, a partir de Ley de Aguas de 1972, donde se aprecia cómo se decidió actualizar la normativa en base a la Constitución aprobada en el año 2008, es en el artículo 411, con énfasis en la sustentabilidad de los ecosistemas y el consumo humano serán prioritarios en el uso y aprovechamiento del agua.

La Ley de Aguas que, en cierto sentido, rige hasta la actualidad constituye un verdadero hito respecto de la propiedad de las aguas en el Ecuador, en razón de que cerró definitivamente toda posibilidad de ejercer cualquier forma de propiedad privada sobre las fuentes y cauces naturales, hasta el punto de prever expresamente que todas las aguas de propiedad particular, existentes hasta entonces, pasaban al dominio público; y, que sus propietarios se transformaban en meros titulares de derechos de aprovechamiento. 
La protección del medio ambiente como un derecho de las personas y un deber primordial del Estado cuenta hoy con una nueva instancia de control normada en la Ley Orgánica de la Contraloría General del Estado, en su artículo 22, llamada a realizar la auditoría sobre temas ambientales en los términos establecidos en la Ley de Gestión Ambiental. Con este propósito, el máximo órgano contralor resolvió expedir, "Las normas técnicas de control externo ambiental". Dentro de este contexto, en la Ley Orgánica del Servicio Público, se establecen los deberes y prohibiciones que tienen que seguir los servidores públicos dentro de sus instituciones para que sean o no sancionados según como la ley disponga. En el artículo 22, de esta Ley, en el literal $b$, se establece que el funcionario público deberá cumplir personalmente con las obligaciones de su puesto, con solicitud, eficiencia, calidez, solidaridad y en función del bien colectivo, con la diligencia que emplean generalmente en la administración de sus propias actividades.

También, en la Ley de Gestión Ambiental, la ley establece varios principios e instrumentos de gestión ambiental y constituye por lo tanto un instrumento jurídico que delinea el campo de acción del Estado y de la sociedad civil ambiental. Se establece los principios y directrices de la política ambiental determinando las obligaciones, responsabilidades, niveles de participación de los sectores público y privado en la gestión ambiental y señala los límites permisibles, controles y sanciones en materia ambiental. Pero adolece de una mirada al impuesto por vertido, así como a los permisos negociables, en atención a la evolución del Derecho Ambiental (Antúnez, 2018).

Ello permite a los autores del ensayo, asociar la bioética como el campo normativo particular en la atención y el cuidado de la vida y de la salud, con los derechos humanos como 
el campo normativo universal básico de las obligaciones morales y jurídicas para todas las formas de vida, se identifican los valores fundamentales de una ética universal sustentada por la dignidad humana, por la igualdad de derechos, por la libertad, por la justicia, por la fraternidad y por la paz, valores claramente observados en las constituciones de Ecuador en lo que se refiere a la protección (defensa) de la naturaleza como sujeto de derechos. Para ello, se justiprecia que la bioética refuerza la propuesta de la visión Pachamama, en la cual el hombre deja de ser visto como el centro del universo y señor absoluto de la naturaleza, y pasa a ser cuestionado por las transformaciones que genera en la biósfera. La tecnología creada por el hombre genera poder, que, a su vez, genera responsabilidad, tanto frente a las generaciones futuras, como a la naturaleza como un todo (Peña, 2018 y Antúnez, 2015).

Para este propósito existen normativas regulatorias en los documentos: Plan de Desarrollo para el Buen Vivir (artículos 1, 13, 32, 33, 34, 35, 281), Ley Orgánica del Régimen de Soberanía Alimentaria (artículos 1, 5, 7), el Sistema Único de Manejo Ambiental (SUMA), y, Texto Unificado de Legislación Ambiental secundaria (TULAS), demuestran que las políticas públicas en la nación de Ecuador tienen un enfoque bioético.

En el Código Orgánico Integral Penal ecuatoriano, implanta sanciones, multas y prisión por contaminación ambiental de ríos y vertientes hay que obedecer y cumplir las disposiciones legales para que en lo posterior no tener inconvenientes. En el artículo 251. Delitos contra el agua "La persona que, contraviniendo la normativa vigente, contamine, deseque o altere los cuerpos de agua, vertientes, fuentes, caudales ecológicos, aguas naturales afloradas o subterráneas de las cuencas hidrográficas y en general los recursos hidrobiológicos o realice descargas en el mar provocando daños graves, será sancionada con una pena privativa de libertad de tres a cinco años". 
Se impondrá el máximo de la pena si la infracción es perpetrada en un espacio del Sistema

Nacional de Áreas Protegidas o si la infracción es perpetrada con ánimo de lucro o con métodos, instrumentos o medios que resulten en daños extensos y permanentes. Según el tipo de delito o infracción se aplica las penas, las áreas protegidas pertenecen al Estado es prohibido cometer daños ambientales. Este Código Orgánico Integral Penal tipifica delitos contra el ambiente y la naturaleza o Pachamama, comprendidos en los artículos del 245 al 267. La tipificación de delitos ambientales plantea dos cuestiones de particular relevancia: la aplicación del principio non bis in idem y el principio de legalidad con referencia a la ley penal en blanco.

La contabilidad ambiental, Mantilla Pinilla, la define como:

"El sistema que permite reconocimiento, organización, valoración y registro de las condiciones y los cambios en los recursos naturales y del ambiente, articulando indicadores de evaluación de la sostenibilidad ambiental en el contexto del desarrollo, estableciendo sistemas de información que faciliten el control y fiscalización de las acciones que afectan la condición de la naturaleza" (Mantilla, 2006).

Plantea este autor referenciado que, la contabilidad ambiental se debe preocupar por el desarrollo de la sostenibilidad de la organización en términos económicos, sociales y medioambientales en función del bienestar y la supervivencia de la sociedad. Por tanto, el propósito de la contabilidad ambiental es suministrar información para evaluar la sostenibilidad de los recursos en el marco del desarrollo sostenible; según el autor "si bien los propósitos se asemejan a los de la contabilidad tradicional -servir de herramienta de evaluación y control-, sus características obligan la adopción de una dinámica especial”. 
En este orden, el agua es considerada dentro de la contabilidad ambiental como un activo ambiental físico, los activos ambientales físicos se dividen en activos ambientales producidos por el hombre (es decir, los cultivados) y los activos ambientales no producidos por el hombre que proporciona la naturaleza; todos los activos naturales se reconocen cuando existe una unidad institucional que ejerce un derecho de propiedad, individual o colectivo sobre un bien, en este caso un bien natural como las tierras de los campos, los activos del subsuelo, los bosques no cultivados, los yacimientos minerales, los ríos, lagos etc., son denominados activos ambientales, siempre y cuando se deriven de ellos beneficios económicos (Gray \& Bbebbington, 2002).

En la nación de Ecuador, el Ministerio del Ambiente asumió en el 2012, a través del Sistema de Contabilidad Ambiental Nacional, la responsabilidad de ejecutar el compromiso Presidencial de desarrollar la contabilidad ambiental. En atención a que, en este sentido, las Naciones Unidas a través del marco central sistema de contabilidad ambiental y económica (SEEA, 2014) y el sistema de contabilidad ambiental y económica para el agua (SEEA-Agua, 2013) proporcionan un marco conceptual para organizar de manera coherente y sistemática la información sobre cuestiones hidrológicas y económicas (AA.VV, 2014).

La estructura de cuentas contables ambientales se desagrega de la siguiente manera: Activos Ambientales, Pasivos Ambientales, Capital Ambiental, Costos y Gastos Ambientales, Medición y Valoración Ambiental, estas definiciones se basan en la formulación desarrollada por la ONU en su estudio denominado Sistemas Contables Ambientales y la Economía Integrada SCAEI (2002)3 sobre la integración de lo ambiental con lo económico.

La contabilidad ambiental promueve la elaboración de la matriz híbrida de ofertautilización ambiental de los activos, flujos ambientales y transacciones económicas conexas para el Ecuador. Por consiguiente, la delimitación de los activos que establece el SCN ya se 
incluye una pequeña parte de los activos de agua, en este caso incluye aguas superficiales y subterráneas para la extracción. Pero en el SEEA-Agua la delimitación de los activos del agua es más amplia, y abarca todas las masas de agua internas.

La contabilidad del agua también permite realizar análisis del agua como insumo para las actividades de producción, como consumo final, y como "sumidero" de desechos o receptor de aguas residuales. Hay que aclarar que se considera al agua como fuente de apoyo a los hábitats y a los ecosistemas, únicamente en los aspectos relativos a la calidad del agua Otra manera en que la economía y la sociedad pueden utilizar el agua es con fines de recreación, navegación, de pesca y otros usos basados en la presencia física del agua (usos in situ). (ONU, 2013).

Los retos de la contabilidad ambiental es proporcionar datos que resaltan tanto la contribución de los recursos naturales al bienestar económico como los costos impuestos por la contaminación o el agotamiento de estos al destacarse la importancia que tiene la contabilidad como herramienta para medir los fenómenos económicos y la utilidad para la toma de decisiones de los diferentes individuos, la contabilidad ambiental toma una gran relevancia para establecer el grado del impacto que presenta la aplicación de políticas y los instrumentos para su regulación y control sobre el medio ambiente, por ello es necesario establecer los parámetros que esta pueda brindar toda la información que sea pertinente, viable, y relevante para su conformación dentro del ámbito social mundial. Son elementos que se valoran que permite la ejecución de la función auditora en la materia ambiental a la Contraloría General en Ecuador. 
El tributo ambiental, en inicio del siglo XXI, los sistemas tributarios han afrontado nuevos retos como la globalización, los avances tecnológicos y la sensibilización de los ciudadanos en los temas sociales. Además, las estructuras tributarias latinoamericanas han experimentado una serie de cambios influenciando por los bajos niveles de recaudo, también cabe mencionar la marginalidad de tributos ambientales introducidos en las sucesivas reformas. El contexto Latinoamericano algunos países han desarrollado en mayor o menor medida su normativa o legislación ambiental (Aguilera, 2011).

El Estado ecuatoriano como sujeto activo en recaudación de impuestos, Constitución Política del Ecuador (2008), artículo 261, establece, “competencia para precisar las políticas económicas, tributarias, así como también en los recursos minerales, hidrocarburíferos y la biodiversidad"; por otra parte, el artículo 300, del cuerpo constitucional señala que "la política fiscal incentivará a la redistribución e impulsará el trabajo creativo innovador, la producción de bienes y servicios, y conductas ecológicas, sociales responsables". El régimen tributario se rige por los principios de generalidad, progresividad, eficiencia, simplicidad administrativa, irretroactividad, equidad, transparencia y suficiencia recaudatoria. Este cuerpo jurídico prioriza los impuestos directos y progresivos. La política tributaria establecida en la nación tiene el objetivo de promover la redistribución y estimular el empleo, la producción de bienes y servicios, y conductas ecológicas, sociales y económicas responsables, hecho jurídico que se vincula con la Ley de Fomento Ambiental y Optimización de los Ingresos del Estado.

Con la aparición de la Ley de Fomento Ambiental y Optimización de los Ingresos del Estado, los impuestos ambientales se han convertido en tema de mucha importancia y relevancia no solo a nivel del Estado ecuatoriano, sino que se ha dilatado en todo el universo por la integración de los países miembros de preservar el ecosistema y el derecho a vivir en un hábitat saludable. Los impuestos ambientales, basados en los principios constitucionales, 
logran los objetivos y elementos normativos frente a la obligación con sus ciudadanos de reconocerles el derecho a vivir en un ambiente saludable y ecológicamente equitativo, que reconozca la sostenibilidad y el Buen Vivir (del concepto kichwa Sumak Kawsay, del aymara Suma Qamaña y del inglés Good Living) y, por otro lado, de la responsabilidad y deberes de los contribuyentes de promover el bien común y anteponer el interés general al interés particular, en sintonía con la política del Buen Vivir, así como también el respeto a la naturaleza y la preservación de un ambiente higiénico y saludable

Los impuestos ecológicos fueron instituidos para minimizar las altas masas de contaminaciones existentes, creadas por las emisiones de gases tóxicos. El Gobierno Nacional, a través del Servicio de Rentas Internas (SRI), concentra una carga impositiva a los vehículos que más intoxican el medio natural, que son los de más alto cilindraje. Asimismo, considera la inserción de un impuesto a las botellas plásticas no retornables (PET), considerando un gravamen que incentiva la reutilización de los mismos. El SRI propone a la ciudadanía la compra de vehículos híbridos de reducido cilindraje, para minimizar las dispersiones nocivas.

A partir del año 2011, en Ecuador, la Asamblea Nacional aprueba el proyecto de ley enviado por el Ejecutivo, donde reconocen la incorporación del impuesto ambiental a la contaminación vehicular y el impuesto redimible a las PET, con la finalidad de minimizar la contaminación ambiental producida por los gases contaminantes de desechos sólidos y la indiscriminada ocupación de las botellas plásticas en las calles, aceras, botaderos de basuras, rellenos sanitarios, entre otros lugares públicos y privados, que afectaba la salud de la ciudadanía y la preservación natural del ecosistema. 
No obstante, hay que significar que los tipos de impuesto vinculados a la contaminación ambiental se aprecian dirigidos a la disminución de gases tóxicos a la atmósfera por el uso de automóviles y el del reciclaje de envases de plástico. Empero, en el ordenamiento jurídico en la nación ecuatoriana no hay una regulación dirigida a la contaminación ambiental como resultado de la extracción de minerales, la contaminación por residuales de las industrias, por la extracción de hidrocarburos, entre otras.

Por tal motivo es un requisito indispensable contar con una política ambiental armonizada a nivel nacional y a nivel local, así como a nivel de otras divisiones relevantes desde el punto de vista de los ecosistemas (como cuencas hidrográficas, zonas frágiles, etc.); y, por supuesto, la política ambiental debe provenir de una institucionalidad fuerte, capaz de ganarse un espacio central y de hacer cumplir sus disposiciones. Los principales obstáculos que enfrentaría una propuesta de reforma fiscal verde en Ecuador son producto de las estructuras económicas y los arreglos sociales que se han creado alrededor de éstas: una economía altamente dependiente de los recursos naturales, especialmente de la explotación de petróleo y de la agricultura de exportación, ha generado una sociedad "rentista", poco productiva, esperanzada en los frutos de la tierra.

Se aprecia que, con la tributación ambiental aplicada como el instrumento que coadyuvará al resto de medidas de política ambiental y energética, y que no solo debería permitir cumplir con el principio de quien contamina paga del Derecho Ambiental, sino que debería incentivar la realización de conductas que reduzcan la contaminación, o desincentivar actividades contaminantes, apartándose de figuras que obedecen exclusivamente a una finalidad recaudatoria. Un caso a destacar en materia de contaminación en Ecuador, es el de la Compañía Texaco-Chevron sobre su responsabilidad por daños provenientes del vertido del 
"agua de formación" que sale con el petróleo en "piscinas" sin adecuado revestimiento y daños del regado de crudo en las vías, daños a otros terrenos y estructuras.

La ley ambiental como instrumento legal para la recaudación tributaria, solidaria con los espacios desprotegidos y la naturaleza, desde el punto de vista jurídico, proporciona lineamentos constitucionales que deben ser atendidos por todas las personas naturales o sociedades que tengan como actividad económica la exploración, explotación y transformación de productos contaminantes que pongan en riesgo la salud de los seres vivos y el medio ambiente. Estos tienen el derecho y la responsabilidad de contribuir con el Estado a través de la participación de los impuestos verdes para la remediación de los daños ambientales y la prevención de los mismos con un enfoque bioético.

\section{Conclusiones}

En Ecuador, el reconocimiento del agua como un derecho humano fundamental y como sujeto de derechos dentro del marco de los derechos de la naturaleza en clave constitucional han revolucionado al mundo, y con ello la teoría del Derecho. La pertinencia de la bioética refuerza la propuesta de la visión Pachamama como garantía constitucional, en la cual el hombre deja de ser visto como el centro del universo y señor absoluto de la naturaleza, y pasa a ser cuestionado por las transformaciones que genera en la biósfera. La tecnología creada por el hombre genera poder, que, a su vez, genera responsabilidad, tanto frente a las generaciones futuras, como a la naturaleza como un todo en pos de alcanzar el desarrollo sostenible cumpliendo los principios del Derecho Ambiental.

La política ambiental armonizada a nivel nacional y local, desde el punto de vista de los ecosistemas debe provenir de una institucionalidad fuerte, capaz de ganarse un espacio central 
y de hacer cumplir sus disposiciones jurídicas. Hoy en Ecuador hay multiplicidad de disposiciones jurídicas, pero en materia de aguas pervive la contaminación por vertido, sin una adecuada mirada del principio de quien contamina paga a través del impuesto ambiental.

La contaminación ambiental incide de forma negativa sobre la naturaleza y el patrimonio de las personas; afecta la salud y las especies biológicas que viven en el planeta, es una obligación buscar las alternativas idóneas para la solución de la problemática ambiental al no la utilizar tecnologías de punta que no afecten al medio ambiente; las disposiciones jurídicas relacionadas con el marco jurídico de la Ley de Gestión Ambiental ecuatoriana requieren llenar los vacíos jurídicos como consecuencia del avance del Derecho Ambiental agravados por la multiplicación e incremento de los procesos extractivos al no usar tecnologías limpias por los sujetos de gestión económico.

La contabilidad ambiental promueve la elaboración de la matriz híbrida de ofertautilización ambiental de los activos, flujos ambientales y transacciones económicas conexas para el Ecuador, lo que permite ejecutar la auditoría ambiental dentro de la fórmula estímulo/recompensa para una mejor competitividad de las empresas públicas y las privadas, necesitada de formación jurídica ambiental.

Los principales obstáculos que enfrentaría realizar una propuesta de reforma fiscal verde en Ecuador seria producto de las estructuras económicas y los arreglos sociales que se han creado alrededor de éstas una economía altamente dependiente de los recursos naturales, especialmente de la explotación de petróleo y de la agricultura de exportación, lo que ha generado una sociedad "rentista", poco productiva, esperanzada en los frutos de la tierra. El reto es modificar estas conductas a través de la formación ambiental con un enfoque bioético.

La tributación ambiental coadyuvará a modificar las medidas de política ambiental y energética en Ecuador, para cumplir con el principio de quien contamina paga, y con ello 
Revista Ciencias Sociales y Económicas - UTEQ (2019)

ISSN 2588-0586 IMPRESO; ISSN 2588-0594 ELECTRÓNICO

Volumen 3, Número 1. Semestral (enero-junio)

incentivar la realización de conductas que reduzcan la contaminación, o desincentivar actividades contaminantes, apartándose de figuras que obedecen exclusivamente a una finalidad recaudatoria a través del impuesto por vertido, con una cultura tributaria.

\section{Referencias bibliográficas}

AA.VV. (2010) Impuestos verdes: una herramienta para la política fiscal en Latinoamérica, Centro de Estudios Fiscales, Fundación Friedrich Ebert, Ecuador.

AA. VV. (2008) Derecho de aguas en Brasil y España, un estudio comparado, Editorial Fortaleza, Brasil.

AA. VV. (2012) Agua y ciudades, $1^{\text {ra }}$ edición, Editorial Civitas, España.

AA. VV. (2007) Bioética y medio ambiente, Editorial Félix Varela, La Habana.

AA. VV. (2013) Bioética para la toma de decisiones, $2^{\mathrm{a}}$ edición, Editorial Universidad de Guanajuato, México.

AA.VV. (2016) Derecho Ambiental. Historia del Derecho Ambiental. Universidad de Buenos Aires. Disponible en: http://federacionuniversitaria71. blogspot.com/2008/09/historiadel-derecho-ambiental.html

AA. VV. (2011) Retos y tendencias del Derecho Ambiental contemporáneo, Editorial ONBC, La Habana.

AA. VV. (2014). Manual sobre Derecho Ambiental ecuatoriano, Editorial Nación, Quito.

AA. VV. (2015). Del concepto a la medición Propuesta metodológica para medir el Buen Vivir en Ecuador, Instituto Nacional de Estadística y Censos, Ecuador.

Acosta A. (2010). El agua, un derecho humano no un negocio. Disponible en: http://www.rebelion.org/noticias/2010/5/105741.pdf 
Acosta, A. et al. (2010). El agua un derecho humano fundamental, Editorial Abya-Yala, Quito.

Acosta, A. (2010). Derecho al agua, Editorial Abya-Yala, Quito.

Afonso Da Silva, J. (2009). Derecho Ambiental Constitucional, Editorial Método, Brasil.

Aguilar Rojas, G. et al. (2009). Derecho Ambiental en Centroamérica, Tomos I y II, Editorial Diseño, Suiza.

Aguilera Klink, F. et al. (2011). De la economía ambiental a la economía ecológica, Editorial Ikaria, España.

Alferillo, P. et al. (2015). Temas de Derecho Procesal Ambiental, Editorial Fusma, Argentina.

Alenza García, J. (2001). Manual de Derecho Ambiental, Editorial Universidad Pública de Navarra, Pamplona.

Albán Gómez, E. (2016). Manual de Derecho Penal ecuatoriano, Editorial Legales, Ecuador.

Albán Gómez, E. (2007) Los delitos contra el medio ambiente en el Código Penal ecuatoriano, Editorial Foro, Ecuador.

Albán Gómez, E. (1987). Documento Jurídico Ecológico, Editorial Mimeográfica, Quito.

Albán, M. (2010). Derecho y cambio climático en los países Amazónicos. Recomendaciones y propuestas Ecuador, Editorial Centro ecuatoriano de Derecho Ambiental, Quito.

Astorga, E. (2007). Derecho Ambiental chileno, Editorial Lexis Nexis, Santiago de Chile.

Aranguren, J. C. (2006). Del desarrollo sostenible a la sostenibilidad. Pensar globalmente y actual localmente, Revista de Derecho Urbanístico y Medio Ambiente, $N^{\circ}$. 226, España, pp.139-211

Amores Terán, O. (1991). Derecho Ecológico ecuatoriano, Editorial Corporación Nacional, Quito. 
Amores Terán, O. (1986). Prontuario de Jurisprudencia Ecológica y Ambiental ecuatoriana, Fundación Natura, Quito.

Amparo Rodríguez, G. (2012). Temas de Derecho Ambiental. Una mirada desde lo público, $1^{\text {ra }}$ edición, Editorial Universidad del Rosario, Colombia.

Aniza García (2008). El Derecho Humano al Agua, Editorial Trotta, España.

Antúnez Sánchez, A. (2016). La inspección ambiental. La evaluación de impacto ambiental. La autorización ambiental y la auditoría ambiental, Revista de Derecho, UNED, $\mathrm{N}^{\mathrm{o}} 18$, España, pp.1-40.

Antúnez Sánchez, A. (2013). Reflexiones en torno a la protección de los derechos humanos desde la perspectiva del Derecho Ambiental Internacional, Revista FIMA, Chile.

Antúnez Sánchez, A. (2015). La auditoría ambiental: Una revisión y propuestas en clave de su función pública y dimensión empresarial. Revista Iberoamericana de Contabilidad de Gestión, $N^{0} 26$, España.

Antúnez Sánchez, A. (2015). Nuevas tendencias de la auditoría con enfoque ambiental para proteger la naturaleza, Revista Redesma, Bolivia.

Antúnez Sánchez, A. (2018). La formación ambiental. Una necesidad en el siglo XXI con el nuevo saber ambiental, Revista Murmullos del Sur, UNAM, México.

Antúnez Sánchez, A. \& Guanoquiza Tello, L. (2017). La protección penal ambiental en Ecuador, Revista Derecho y Cambio Social, Perú.

Antúnez Sánchez, A. (2018). La ecoauditoría en el modelo de la Comunidad Europea y de América Latina. $\mathrm{N}^{\mathrm{o}}$. 55, Revista de Derecho Ambiental. Doctrina, jurisprudencia, legislación y práctica. Editorial Abeledo Perrot S.A. Argentina. 
Andaluz, C. (2006). Manual de Derecho Ambiental, Editorial Proterra, Perú.

Angulo, M. (2013). Manual práctico de Derecho Ambiental. La Naturaleza como Sujeto de Derecho. Doctrina Práctica y Jurisprudencia, Editorial Workhouse, Quito.

Agenda 2030, los Objetivos de Desarrollo Sostenible (2018). Una oportunidad para América Latina y el Caribe, CEPAL.

Báez, O. (2009). La certificación ambiental: nuevo reto y oportunidad, Editorial Universidad Central del Ecuador, Quito.

Beltrao, A. (2011). Direito Ambiental, $3^{a}$ edición, Editorial Método, Brasil.

Buckalew, J. et al. (1998). Evaluación de los recursos de agua del Ecuador. Editorial Centro de Ingeniería y Topografía, Estados Unidos de América.

Bustamante Alsina, J. (1995). Derecho Ambiental, fundamentación y normativa, $1^{\text {ra }}$ edición, Editorial Abeledo Perrot, Argentina.

Betancor Rodríguez, A. (2014). Derecho Ambiental, $1^{\text {a }}$ edición, Editorial Las Rosas, Madrid.

Betancor Rodríguez, A. (2001). Instituciones de Derecho Ambiental, Editorial La Ley, Madrid.

Bellorio Clabot, D. (2004) Tratado de Derecho Ambiental, $1^{a}$ edición, Editorial Astrea, Buenos Aires.

Bellorio Clabot, D. et al. (2010) Derecho ambiental de aguas, Editorial Grafica del Sur, Argentina.

Bifani, P. (1999) Medio ambiente y desarrollo sostenible, $4^{\mathrm{a}}$ edición, Editorial Madrid, España.

Bustamante Alsina, J. (2012) Derecho Ambiental, Editorial Abeledo Perrot, Argentina. Botassi, C. (1997) Derecho Administrativo Ambiental, Editorial Platense, La Plata. 
Borja y Borja, R. (1979) Derecho Constitucional ecuatoriano, Editorial cultura hispánica, Madrid.

Brañes Ballesteros, R. (2003) La fundación del Derecho Ambiental en América Latina, PNUMA, Chile.

Brewer Carias, A. (1976) Derecho y Administración de las aguas y otros recursos renovables, Editorial Universidad Central de Venezuela, Caracas.

Bhrunis Lemarie, R. (2010) El constitucionalismo en el Ecuador, Editorial Alter Justitia, Quito.

Blacio Aguirre, G. (2012) Texto comentado a la Constitución de la República del Ecuador, $1^{\mathrm{a}}$ edición, Editorial Biblos Lex, Loja.

Cafferata, N. (2004) Introducción al Derecho Ambiental, Editorial INE-Semarnat, México.

Caferrata, N. (2013) Análisis del marco regulatorio en los países de América Latina y el Caribe. Economía verde en el contexto del desarrollo sostenible y erradicación de la pobreza, PNUMA, Argentina.

Caraballo Maqueira, L. (2012) Derecho y Medio Ambiente. Consideraciones generales. Respuesta de las ciencias jurídicas a los problemas ambientales, Editorial Pablo de la Torriente, La Habana.

Cavali, L. (2007) Derecho de Aguas, Editorial Universidad de Belgrano, Argentina.

Clabot, D. \& Pigretti, E. (2013) Derecho Ambiental de Aguas, Editorial Lajouane, Argentina.

Constitución Política de la República del Ecuador, Registro Oficial N ${ }^{\circ} .449$, de 20 de octubre 2008.

Codificación a la Ley de Aguas, 2004. Registro oficial No 339, de 20 mayo 2014. 
Código Civil, 2002. Corporación de Estudios y Publicaciones.

Código Penal. Ley No. 99-49, Registro Oficial N² 2, de 25 de enero del 2000.

Código Orgánico Integral Penal. Registro Oficial Nº . 180, de 10 de febrero de 2014.

Código Orgánico Integral Penal. Corporación de Estudios y Publicaciones, Ecuador. 2014.

Conesa García, V. et al. (2004) Medio Ambiente, Editorial Universidad de Murcia, España.

Conesa Fernández, V. (1997) Instrumentos de la gestión ambiental en la empresa, $1^{\text {a }}$ edición, Editorial Mundi-Prensa, España.

Contraloría General del Estado (2013) Guía auditoría ambiental, base legal para auditorías ambientales con enfoque a Temas de agua, residuos sólidos y líquidos, Ecuador.

Corte Constitucional Decreto Ejecutivo $\mathrm{N}^{\mathrm{o}}$ 1088. Registro oficial 15 de mayo del 2008. Creación de la Secretaría Nacional del Agua, SENAGUA. Decreto Ejecutivo N ${ }^{0} 1449$. Registro Oficial 479, del 2 de diciembre de 2008.

Cuenca Tovar, R. et al. (2018) Cuestiones actuales de Derecho Ambiental, Editorial Universidad Manuela Beltrán, Colombia.

Crespo Plaza, R. (1995) Manual legal sobre el medio ambiente en el Ecuador, Comisión Asesora Ambiental de la Presidencia de la República, Ecuador.

Crespo Plaza, R. (2015) Algunos casos de retroceso de la legislación ambiental del Ecuador, Editorial Gland, Quito.

Crespo Plaza, R. (2008) Texto guía legislación ambiental, Universidad Técnica de Loja, Ecuador.

Da Silva, J. (2007) Direito Ambiental Constitucional, $6^{\text {a }}$ edición, Editorial Malheiros, Brasil.

Ditto, J. (1999) Derecho Ambiental, Editorial Guayaquil, Ecuador.

De Besa Antunes, P. (2011) Derecho Ambiental, Editorial Lumen Juris, Brasil.

De Los Ríos, I. (1993) Derecho del Ambiente, $2^{\text {a }}$ edición, Editorial de los Ríos, Caracas. 
Revista Ciencias Sociales y Económicas - UTEQ (2019)

ISSN 2588-0586 IMPRESO; ISSN 2588-0594 ELECTRÓNICO

Volumen 3, Número 1. Semestral (enero-junio)

De Medeiros García, L. (2010) Derecho Ambiental Constitucional. El derecho interno ambiental a partir de la protección constitucional, $2^{\mathrm{a}}$ edición, Editorial Jus Podivm, Brasil.

Di Trindade Amado, F. (2011) Derecho Ambiental Esquematizado, Editorial Método, Brasil.

D’ Estéfano Pisani, M. (1996) Derecho Ambiental Internacional, Editorial Ciencias Sociales, La Habana.

Estenssoro Saavedra, F. (2014) Historia del debate ambiental en la política mundial 19451992. La Perspectiva Latinoamericana, Editorial Idea, Chile.

Esteve Pardo, J. (2008) Derecho del medio ambiente, 2a edición, Editorial Marcial Pons, España.

Embid Irujo, A. (2011) La crisis del agua, de la agricultura y de las finanzas públicas. El papel del Derecho, Agua y Agricultura, Editorial Aranzadi, Navarra.

Embid Irujo, A. et al. (2006) El Derecho al Agua, Editorial Thomson-Aranzadi, Navarra.

Elbers, J. (2013) Ciencia holística para el buen vivir: una introducción, Centro Ecuatoriano de Derecho Ambiental, Quito.

Fernández Ruiz, J. (2007) Régimen jurídico del agua, cultura y sistema jurídicos comparados, Editorial UNAM, México.

Fernández, P. (2009) Manual de Derecho Ambiental, Editorial Jurídica de Chile, Santiago de Chile.

Fernández De Gatta Sánchez, D. (2008) Derecho Ambiental, Editorial Trivium, España.

Fernández-Rubio Legrá, Á. (2000) La legislación ambiental contemporánea: logros y fracasos, algunas reflexiones críticas, Editorial Academia, La Habana. 
Fernández-Rubio Legrá, A. (1996) Derecho Ambiental internacional, Editorial AFR, La Habana.

Field, B. (1995) Economía Ambiental: Una introducción, Editorial McGraw Hill, Colombia.

Guaranda, W. (2009) Estudio Comparado de Derecho Ambiental, Editorial INREDH, Quito.

García, A. (2008) El derecho humano al agua, Editorial Trotta, Madrid.

García Minella, G. (2004) Derecho Ambiental. Su actualidad de cara al tercer milenio, Editorial Ediar, Argentina.

Gudynas, E. (2011) Los derechos de la naturaleza en serio. Respuestas y aportes desde la ecología política. La Naturaleza con Derechos. De la filosofía a la política, Editorial Abya-Yala, Quito.

Gudynas, E. (2009) La ecología política del giro biocéntrico en la nueva Constitución de Ecuador, Revista de Estudios Sociales, N ${ }^{\mathrm{O}}$ 32, México, pp.34-47.

González Márquez, J. (2008) Teoría del Derecho Ambiental. Los fundamentos jurídicos de la sostenibilidad. Editorial IMDA. México.

González Novo, T. (1998) Cuba, su medio ambiente después del medio milenio, Editorial Científico-Técnica, La Habana.

Gray, R. \& Bebbington, J. (2002) Contabilidad y auditoría ambiental. Editorial ECOE, Bogotá.

Grijalva Jiménez, A. (2012) Constitucionalismo en Ecuador, Editorial Corte Constitucional del Ecuador, Quito.

Grijalva Jiménez, A. (2010) Régimen constitucional de biodiversidad, patrimonio cultural y ecosistemas frágiles, y recursos renovables. Desafíos del Derecho Ambiental ecuatoriano frente a la Constitución vigente, Editorial Centro ecuatoriano de Derecho Ambiental, Quito. 
Harlem Burtland, G. (1984) Informe Nuestro Futuro Común, ONU.

Hava García, E. (2011) Delitos contra los recursos naturales y el medio ambiente, Editorial Tirand lo Blanch, Valencia.

Hervé, D. \& Pérez R. (2011) Derecho Ambiental y Políticas Públicas, Universidad Diego Portales, Santiago.

Herrera Molina, P. (2000) Derecho tributario ambiental. Editorial Marcial Pons, España.

Isch E. \& Gentes, I. et al. (2006) Agua y servicios ambientales. Visiones críticas desde los Andes, Editorial Abya-Yala, Quito.

Jaquenod De Zsogon, S. (1991) El Derecho Ambiental y sus principios rectores, Editorial Dykinson, Madrid.

Jaquenod De Zsogon, S. (2004) Derecho Ambiental, $2^{\text {a }}$ Edición, Editorial Dykinson, España.

Jacquenod De Zsogon, S. (2005) Derecho Ambiental, la gobernanza de las aguas, Editorial Dykinson, Madrid.

Jordano Fraga, J. (2009) Derecho Ambiental, Revista Medio Ambiente, España.

Jordano Fraga, J. (1995) La protección del derecho a un medio ambiente adecuado, Editorial José María Bosch, Barcelona.

Jordano Fraga, J. (2003) El Derecho Ambiental del Siglo XXI, Medio Ambiente \& Derecho, Revista Electrónica de Derecho Ambiental, Nº 9, España.

Juste Ruiz, J. (1999) Derecho Internacional del Medio Ambiente, Editorial MacGraw Hill, Madrid.

Larrea Andrade, M. (2008) Derecho Ambiental Ecuatoriano, Editorial Legales EDLE, $1^{\mathrm{a}}$ edición, Quito. 
Larrea Horguín, J. (1999) Derecho Constitucional ecuatoriano, 6 ${ }^{\mathrm{a}}$ edición actualizada, Editorial Corporación de Estudios y Publicaciones, Quito.

Leff Zimerman, E. (2000) Saber Ambiental, Editorial Siglo XXI, México.

León Correa, F. (2008) La bioética latinoamericana en sus textos, $1^{\text {a }}$ edición, editorial Universidad de Chile.

Ley de Aguas. Registro Oficial Nº. 339, de 20 de mayo de 2004.

Ley de Derechos Colectivos de los Pueblos Negros Afroecuatorianos. Ley $N^{\mathrm{o}}$. 46 Registro Oficial No. 275, de 22 de mayo de 2006.

Ley de Gestión Ambiental. Registro Oficial N²45, de 30 de Julio de 1999.

Ley de Gestión Ambiental. Registro Oficial Suplemento N ${ }^{\mathrm{o}}$. 418, Editorial Lexis, Ecuador, 2014.

Ley Orgánica de Recursos Hídricos Usos y Aprovechamiento del Agua. Registro Oficial Suplemento $\mathrm{N}^{\circ}$. 305, Editorial Lexis, Quito, 2014.

Ley Orgánica de Salud. Registro Oficial Suplemento Nº 423. Editorial Lexis, Quito, 2006.

Ley de Gestión Ambiental. Ley Nº. 99-37. Registro Oficial Nº 24530 de julio de 1999.

Ley de Prevención y Control de la Contaminación Ambiental. Registro Oficial Suplemento $\mathrm{N}^{\mathrm{o}} .418$ de 10 de septiembre del 2004.

Ley Forestal y de Conservación de Áreas Naturales y Vida Silvestre. Registro Oficial $\mathrm{N}^{\mathrm{o}} 41$ codificación no. 2004-O17.

Ley de Aguas Ley N ${ }^{\circ} .139$ suplemento Registro Oficial Nº. 862 del 28 de enero de 1992.

Ley Orgánica de Tierras Rurales y Territoriales Ancestrales, Registro Oficial N ${ }^{0} .711$ de fecha 14 de marzo de 2016

Ley reformatoria al Código Penal que tipifica el delito de genocidio y etnocidio, Suplemento del Registro Oficial N ${ }^{0} \cdot 578.2009$. 
Revista Ciencias Sociales y Económicas - UTEQ (2019)

ISSN 2588-0586 IMPRESO; ISSN 2588-0594 ELECTRÓNICO

Volumen 3, Número 1. Semestral (enero-junio)

Ley Orgánica del Régimen Especial de la Provincia Galápagos. Registro Oficial N ${ }^{0} .520$ de 11 de junio de 2015.

Llasag Fernández, R. (2011) Los Derechos de la Naturaleza y la Naturaleza de sus Derechos, Editorial Ministerio de Justicia y Derechos Humanos, Quito.

López Sela, A. et. al. (2006) Derecho Ambiental, Editorial Iure, México.

López Menudo, F. (2012) El derecho a la protección del medio ambiente, Universidad de Sevilla, España.

López Barja De Quiroga, J. (2004) El principio "non bis in idem", Editorial Dykinson, Madrid.

Lozano Cutanda, B. (2015) Tratado de Derecho Ambiental. Editorial CEF, España.

Lozano Cutanda, B. \& Allí Turrillas, J.C. (2013) Administración y legislación ambiental, Editorial Dykinson, $7^{\text {a }}$ edición, España.

Lozano Cutanda, B. (2012) Derecho Ambiental Administrativo, Editorial Dikinson, España.

Londoño Rodríguez, B. et al. (2006) Perspectivas del Derecho Ambiental en Colombia, Editorial Universidad del Rosario, Colombia.

Lorenzetti, R. (2008) Teoría del Derecho Ambiental, Editorial Porrúa, México.

Loperena Rota, D. (2003) Desarrollo sostenible y globalización, Editorial ThomsonAranzadi, Argentina.

Leme Machado, P. (2005) Direito Ambiental Brasileiro, $13^{\mathrm{e}}$ edición, Editorial Malheiros, Brasil.

Libster, M. (1993) Delitos Ecológicos, Editorial Depalma, Buenos Aires. 
Lustosa Da Costa, C. E. (2014) Las auditorías coordinadas y sus contribuciones para los Estados Federales: la experiencia de la auditoría en la Amazonía, Revista OLACEFS, $\mathrm{N}^{\mathrm{o}} 15$, Brasil.

Martín, A. \& Santamaría, J. (2000) Diccionario terminológico de la contaminación ambiental. Editorial Universidad de Navarra, España.

Martín Mateo, R. (1991) Tratado de Derecho Ambiental, $1^{\text {a }}$ edición, Editorial Trivium, España.

Martin Mateo, R. (2000) Lecciones de Derecho del Medio Ambiente, 2ª edición, Editorial Lex Nova, Valladolid.

Martín-Retortillo Baquer, S. (1997) Derecho de aguas, Editorial Civitas, Madrid.

Martín-Retortillo Báquer, L. (2006) Derechos fundamentales y medio ambiente, Universidad Complutense de Madrid, España.

Martínez Moscoso, A. (2017) El derecho al agua en el Ecuador. Un análisis desde la Ciencia Política y el Derecho Público, Editorial Universidad de Cuenca, Ecuador.

Maliandi, R. (2008) Teoría y praxis de los principios bioéticos, Editorial Universidad de Lanús, Buenos Aires.

Machado, P. (2002) Direito ambiental brasileiro, 10 a edición, Editorial Malheiros, Sao Paulo, pp.102-103.

Madrigal Cordero, P. (1995) Derecho Ambiental en Centro América, Escuela Judicial de Costa Rica, San José, p. 20.

Mantilla Pinilla, E. (2006) Contabilidad ambiental en el desarrollo sostenible, Revista Legis Internacional de Contaduría y Auditoría, № 25, Colombia, pp. 133-160.

Mancheno Salazar, G. (2004) Práctica del Derecho Ambiental en el Ecuador, Editorial Aplicaciones Gráficas, Quito. 
Martínez Osés, P. (2017) Un análisis del poder en la agenda 2030: oportunidades para un cambio de paradigma de desarrollo. Economistas sin Fronteras. Dossieres EsF, N. ${ }^{\circ}$ 26, España.

Moreano, M. et al. (2016) La política económica de la reforma a la gobernanza del agua y las implicaciones para la desigualdad territorial. El caso de Ecuador, Editorial Centro Latinoamericano para el Desarrollo Rural, Ecuador.

Morales Lamberti, A. (2008) Estudios de Derecho Ambiental, Universidad de Córdova, Argentina.

Morales, M. et al. (2013) El Derecho Ambiental en el Ecuador, Editorial ECOLEX, Quito.

Mora Ruiz, M. (2007) La gestión ambiental compartida. Función Pública y Mercado. Editorial Lex Nova. España.

Mora Roa, G. et al. (2007) Contabilidad y medio ambiente, Editorial Universidad de Quindio, Colombia.

Meier, H. (2003) El Derecho Ambiental y el nuevo milenio, $1^{\text {a }}$ edición, Ediciones Homero, Caracas.

Medeiros García, L. (2010) Direito Ambiental, Editorial Jus Podim, Brasil.

Melo, M. (2009) Los derechos de la Naturaleza en la nueva Constitución ecuatoriana. Derechos de la Naturaleza. El futuro es ahora, Editorial Abya-Yala, Quito.

Merlo, M. (2008) Derecho Ambiental ecuatoriano, Editorial legales EDLE, Quito.

Mejía Soto, Eutimio (2010) Contabilidad ambiental, crítica al modelo de contabilidad financiera. Editorial Optigraf Ltda. Colombia. 
Narváez Quiñones, I. \& Narváez, M. (2012) Derecho Ambiental en clave neoconstitucional. Enfoque político, Editorial Flacso, Quito, pp.11-513.

Narváez Quiñonez, I. (2004) Derecho Ambiental y Temas de Sociología Ambiental, $1^{a}$ edición, Editorial Jurídica Cevallos, Quito.

Navarro Caballero, T. (2007) Los instrumentos de gestión del dominio público hidráulico, Editorial Tirant lo Blanch, Valencia.

Novo Villaverde, M. (2000) Educación Ambiental. Teoría y Práctica, Revista Iberoamericana de Educación. $\mathrm{N}^{0}$. 11, España.

Ortega Álvarez, L. (2012) Tratado de Derecho Ambiental, Editorial Tirant lo Blanch, Valencia.

Ortega Navarro, A. (2012) Derecho de Aguas. Derecho Ambiental, Editorial Tecnos, Madrid.

Oré, M. (2009) El agua ante nuevos desafíos. Actores e iniciativas en Ecuador. Osfam Internacional, Perú.

Oliva, N. (2011) Impuestos Verdes: ¿una alternativa viable para el Ecuador? Centro de Estudios Fiscales, Ecuador.

Paredes, P. (2011) Calidad de las aguas, Editorial ECAPAG, Guayaquil.

Parejo Alfonso, L. (2013) El derecho al medio ambiente y la actuación de la Administración Pública, Editorial Aranzadi, España.

Parejo Alfonso, L. (2008) Código del Medio Ambiente, $6^{\mathrm{a}}$ edición, Editorial Thomson Aranzadi, Pamplona.

Palomar Olmeda, A. (1986) La protección del medio ambiente en materia de aguas, Revista de Administración Pública, $\mathrm{N}^{\circ}$. 110, España.

Páez Pérez, C. (2001) La evaluación de Impactos Ambientales, Editorial Semplades, Quito.

Plaza, C. (2008) El Derecho Humano al Agua, Editorial Ideasamares, Nicaragua. 
Pigretti, E. (2004) Derecho Ambiental profundizado, Editorial La Ley, Buenos Aires.

Pigretti, E. (2012) Derecho Ambiental de aguas. Editorial Lajouane, Buenos Aires.

Pigreti, E. (2007) Ambiente y Sociedad. El bien común planetario, Editorial Lajouane, Buenos Aires.

Pichs Madruga, R. (2008) Cambio climático. Globalización y subdesarrollo, Editorial Científico -Técnica, La Habana.

Prieur, M. (1991) Droit de l'environnement, Editorial Dalloz, $2^{a}$ edición, París.

Peña, M. (2005) El Derecho Humano al Agua, Editorial ANZU, Colombia.

Peña Chacón, M. (2007) Derecho Ambiental, $1^{\text {a }}$ edición, Editorial Jurídica Continental, Costa Rica.

Peña Chacón, M. (2016) Derecho Ambiental efectivo, $1^{\text {a }}$ edición, Editorial Universidad de Costa Rica, San José.

Peña Chacón, M. (2008) Tesis de Derecho Ambiental, Editorial Jurídica Continental, San José.

Peña Chacón, M. (2018) La Revolución de los Derechos Humanos Ambientales y de los Derechos de la Naturaleza, Revista Iberoamericana de Derecho Ambiental y Recursos Naturales, $\mathrm{N}^{\mathrm{o}} .28$, Argentina

Pérez, E. (1995) Derecho Ambiental y de los Recursos Naturales. Editorial EDINO, Ecuador.

Pérez, E. (2008) Derecho Ambiental, Editorial Corporación de Estudios y Publicaciones, Quito. 
Pérez, E. \& Montalvo, R. (1999) Manual de Aplicación de Normas sobre Problemas de Desarrollo Sustentable y Biodiversidad en el Ecuador, Editorial Corporación Latinoamericana para el Desarrollo, Ecuador.

Pérez, E. (2000) Derecho Ambiental, Editorial Mc Graw Hill, Colombia.

Pérez Royo, F. (2009) Derecho financiero y tributario. Edición 20², Editorial Thomson Reuters-Civitas, España.

PNUMA (2013) El constitucionalismo en América Latina con la práctica democrática y la participación ciudadana, ONU.

Poles, V. (2010) Análisis de la aplicación de Derecho Ambiental en la Amazonia ecuatoriana y el rol de las Fiscalías Ambientales, Editorial Centro Ecuatoriano de Derecho Ambiental, Quito.

Rabasa, E. et al. (2008) Agua: aspectos constitucionales, Editorial UNAM, México.

Rodríguez, F. et al. (2008) Derecho Ambiental, Editorial Universitas, Argentina.

Rodríguez-Becerra, M. (2002) Gestión ambiental en América Latina y el Caribe Evolución, tendencias y principales prácticas, Editorial División de Medio Ambiente, Estados Unidos de América.

Rosa Moreno, J. (2000) El Derecho Ambiental en Latinoamérica, Editorial McGraw-Hill, Madrid.

Romero, J. (2012) Derecho Ambiental \& Estatuto Sancionatorio, Editorial Nueva Jurídica, Quito.

Roca, J. \& Puig, I. (2010) Curso de Impuestos Ambientales: Una aproximación desde la Economía Ecológica. Centro de Estudios Fiscales, Quito.

Rey Santos, O. (2013) Fundamentos del Derecho Ambiental, Editorial CIABO-ONBC, La Habana. 
Rey Santos, O. (2016) Derecho y cambio climático. Legislando en un mundo cambiante, Editorial Academia, La Habana.

Reyes López, M. (2001) Derecho Ambiental español, Editorial Tirant lo Blanch, Valencia.

Ruza Tarrio, F. (1993) Tratado del Medio Ambiente, $1^{\text {a }}$ edición, Editorial Aglo, Madrid.

Ruiz-Rico, G. (2010) El Derecho Constitucional del medio ambiente, Editorial Tirant lo Blanch, Valencia.

Santiana, L. (2010) El derecho constitucional al agua, Ecuador. Disponible en: http://www.ohchr.org/Documents/Publications/FactSheet35sp.pdf.

Sanz Larruga, F. (2016) Derecho Ambiental para una economía verde, Editorial Aranzadi, España.

Soriano García, J. \& Brufao Curiel, P. (2013) Claves de Derecho Ambiental III, cuestiones generales del Derecho Ambiental. Editorial Iustel, $1^{\text {a }}$ edición, España.

Salman, M. (2004) El Derecho Humano al agua. The World Bank. Washington.

Salgado Pesantes, H. (2003) Lecciones de Derecho Constitucional, $4^{\mathrm{a}}$ edición actualizada, Editorial Abya-Yala, Quito, 2003.

Sáenz, O. (2007). Las Ciencias Ambientales: una nueva área de conocimiento, Red Colombiana de Formación Ambiental, Bogotá.

Silveira Da Rocha Sampaio, R. (2011) Direito Ambiental, Editorial Elservier, Brasil.

Soler Tormo, I. Tesis doctoral: La configuración constitucional del medio ambiente como derecho, Universidad de Valencia, España (2016)

Serrano, W. (1988) Ecología y Derecho, Editorial Artes Gráficas, Quito.

Teles Da Silva, S. (2010) Direito Ambiental Internacional, Editorial Del Rey, Belo Horizonte. 
Valls, M. (1994) Derecho Ambiental, $3^{\text {a }}$ edición, Editorial Abeledo Perrot, Argentina.

Valenzuela, R. (2010) Derecho Ambiental presente y pasado, Editorial jurídica de Chile, Santiago de Chile.

Vinueza, C. (2011) El Derecho Humano al agua y la justicia ambiental en Ecuador, Editorial FLACSO, Ecuador.

Vergara Blanco, A. (1998) Derecho de aguas, Tomos I y II, editorial Jurídica de Chile, Chile.

Verdesoto Salgado, L. (1988) Estudios de Derecho Constitucional ecuatoriano, Editorial Publicaciones de la Universidad Central, Quito.

Viamontes Guilbeaux, E. et. al. (2007) Derecho Ambiental Cubano, Editorial Félix Varela, La Habana.

Zabala Egas, J. (2010) Derecho Constitucional, neoconstitucionalismo y argumentación jurídica, Editorial Edilex, Guayaquil.

Zaffaroni, E. (2011) La naturaleza con derechos. De la filosofía a la política, Editorial AbyaYala, Quito.

Zaffaroni, E. (2011) La Pachamama y el humano, Editorial Madres de la Plaza de Mayo, $1^{\mathrm{a}}$ edición, Buenos Aires. 